\title{
Using Cost-Effectiveness Analysis to Prioritize Spending on Traffic Safety
}

Liisa Ecola, Benjamin Batorsky, Jeanne S. Ringel 
For more information on this publication, visit www.rand.org/t/rr1224

Published by the RAND Corporation, Santa Monica, Calif.

(C) Copyright 2015 RAND Corporation

RAND $^{\circledR}$ is a registered trademark.

\section{Limited Print and Electronic Distribution Rights}

This document and trademark(s) contained herein are protected by law. This representation of RAND intellectual property is provided for noncommercial use only. Unauthorized posting of this publication online is prohibited. Permission is given to duplicate this document for personal use only, as long as it is unaltered and complete. Permission is required from RAND to reproduce, or reuse in another form, any of its research documents for commercial use. For information on reprint and linking permissions, please visit www.rand.org/pubs/permissions.html.

The RAND Corporation is a research organization that develops solutions to public policy challenges to help make communities throughout the world safer and more secure, healthier and more prosperous. RAND is nonprofit, nonpartisan, and committed to the public interest.

RAND's publications do not necessarily reflect the opinions of its research clients and sponsors.

Support RAND

Make a tax-deductible charitable contribution at www.rand.org/giving/contribute

www.rand.org 


\section{Preface}

This report examines how traffic safety funding could best be spent to reduce motor vehicle crash-related injuries and deaths. We base the analysis and findings here on the data and analysis of an interactive online tool, the Motor Vehicle Prioritizing Interventions and Cost Calculator for States (MV PICCS). RAND Corporation researchers created MV PICCS to support states' and local communities' ability to make evidence-based resource-allocation decisions relating to the implementation of effective interventions for preventing motor vehicle-related injury. The analysis presented here extends the use of the tool to consider how the United States might best allocate scarce resources to implement the most cost-effective motor vehicle-crash countermeasures.

This report will be of interest to national, state, and local health and safety officials seeking information on the effectiveness and costs of the various interventions.

The project had two sponsors and created several products. The National Center for Injury Prevention and Control at the Centers for Disease Control and Prevention (CDC) sponsored the original development of MV PICCS. The tool is hosted online at www.cdc.gov/motorvehiclesafety/calculator/doc. CDC also sponsored the project documentation (Ringel et al., forthcoming), which includes considerable detail on the assumptions and data that underlie the tool. The Robert Wood Johnson Foundation sponsored both this report and additional work to increase the number of interventions analyzed in the tool from the original 12 to 14. This report uses the underlying calculations in the tool to develop several policy analyses - comparisons of different ways to rank the selected interventions at the state or national level based on cost-effectiveness analysis. Finally, four research briefs summarize the tool and the analyses in this report:

- Liisa Ecola and Jeanne S. Ringel, Which Behavioral Interventions Are Most CostEffective in Reducing Drunk Driving? Santa Monica, Calif.: RAND Corporation, RB9826-CDC, forthcoming

- Liisa Ecola, Benjamin Batorsky, and Jeanne S. Ringel, A New Tool to Help Decisionmakers Select Interventions to Reduce Traffic Crash Deaths and Injuries, Santa Monica, Calif.: RAND Corporation, RB-9827-CDC, forthcoming (a)

- Liisa Ecola, Benjamin Batorsky, and Jeanne S. Ringel, How to Get the Biggest Impact from an Increase in Spending on Traffic Safety, Santa Monica, Calif.: RAND Corporation, RB-9855, forthcoming (b)

- Liisa Ecola, Benjamin Batorsky, and Jeanne S. Ringel, Should Traffic Crash Interventions Be Selected Nationally or State by State? Santa Monica, Calif:: RAND Corporation, RB-9860, forthcoming (c). 
The research reported here was conducted jointly in RAND Health and in the RAND Transportation, Space, and Technology Program. Questions or comments about this report should be sent to the project leader, Jeanne Ringel (Jeanne_Ringel@rand.org).

\section{RAND Health}

RAND Health, a division of the RAND Corporation, is one of the largest private health research groups in the world. Currently, between 250 and 300 projects are under way, addressing a wide range of health care policy issues. RAND Health research studies are coordinated through two programs that focus on long-standing core areas of RAND Health's policy research expertise: Health Services Delivery Systems and Population Health.

A profile of RAND Health, abstracts of its publications, and ordering information can be found at www.rand.org/health.

\section{The RAND Transportation, Space, and Technology Program}

The RAND Transportation, Space, and Technology Program addresses topics relating to transportation systems, space exploration, information and telecommunication technologies, nano- and biotechnologies, and other aspects of science and technology policy. Program research is supported by government agencies, foundations, and the private sector.

This program is part of RAND Justice, Infrastructure, and Environment, a division of the RAND Corporation dedicated to improving policy and decisionmaking in a wide range of policy domains, including civil and criminal justice, infrastructure protection and homeland security, transportation and energy policy, and environmental and natural resource policy.

For more information about the Transportation, Space, and Technology Program, see www.rand.org/transportation or contact the director at tst@rand.org. 


\section{Contents}

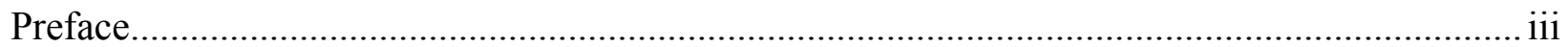

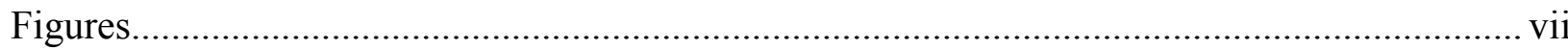

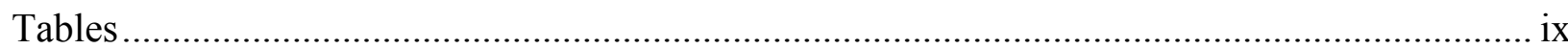

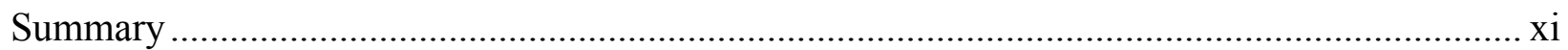

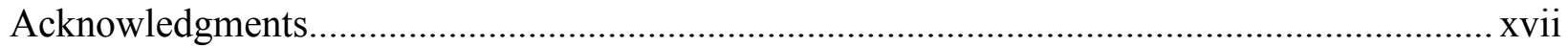

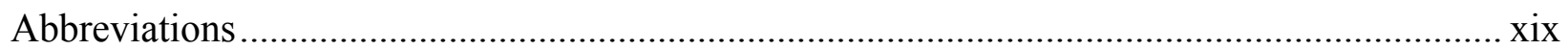

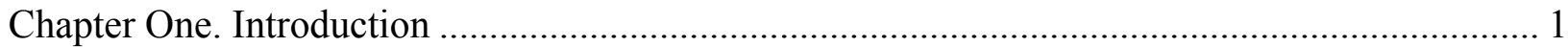

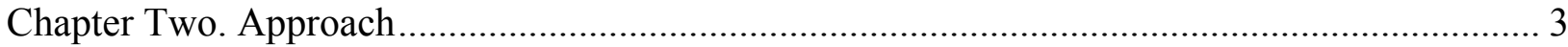

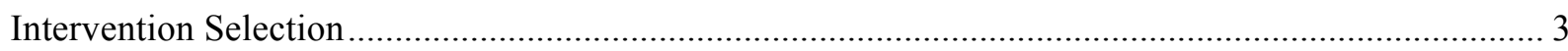

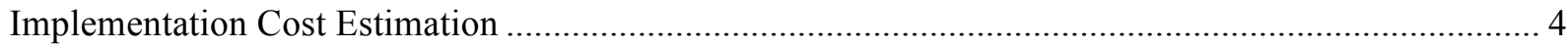

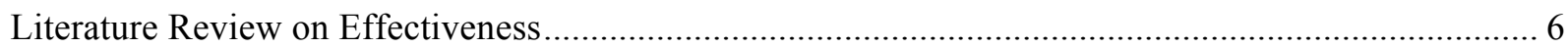

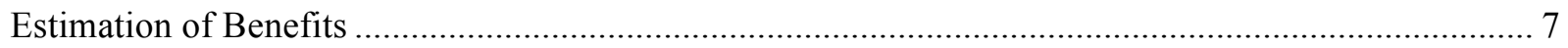

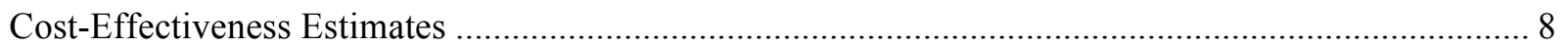

Using the Estimates for National Policy Analysis......................................................................... 9

Chapter Three. What Are the Effects of Implementing the Most Cost-Effective

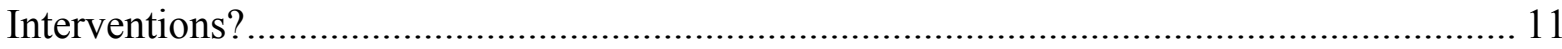

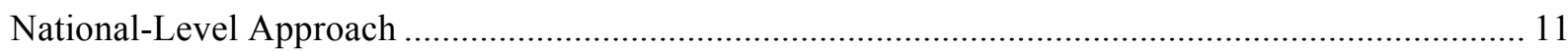

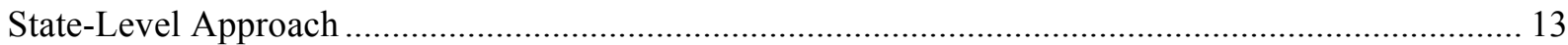

Chapter Four. What Is the Most Cost-Effective Way to Allocate an Increase in Funding for

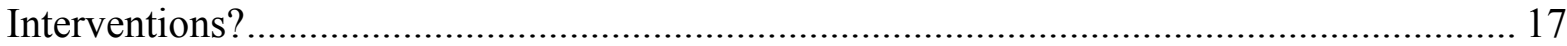

Chapter Five. Given This Set of Interventions, What Is the Most Cost-Effective Way to

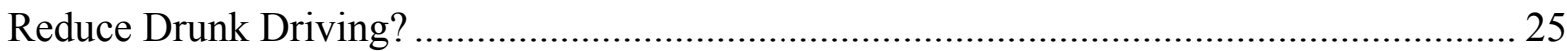

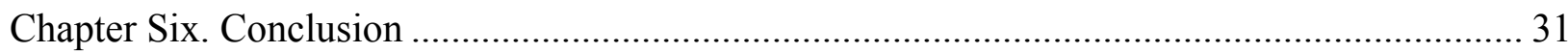

What Are the Effects of Implementing the Most Cost-Effective Interventions? ................................. 31

What Is the Most Cost-Effective Way to Allocate an Increase in Funding for Interventions? .............. 31

Given This Set of Interventions, What Is the Most Cost-Effective Way to Reduce Drunk Driving?.... 32

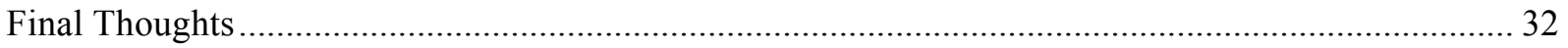

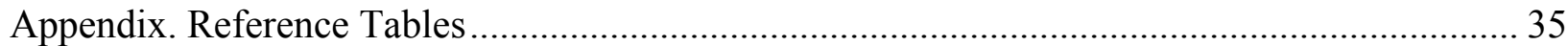

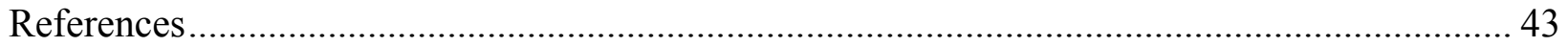





\section{Figures}

Figure 2.1. Scatterplot of Lives Saved and Cost-Effectiveness Ratio for 298 Combinations

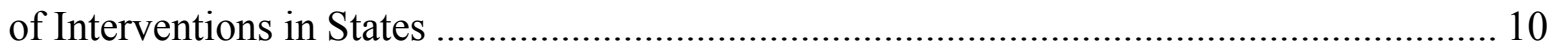

Figure 3.1. Cumulative Cost-Effectiveness Ratios of the 11 Interventions............................... 13

Figure 3.2. Top Intervention for Each State .................................................................... 15

Figure 5.1. Scatterplot of Number of Interventions, by Proportion of Fatalities Related to

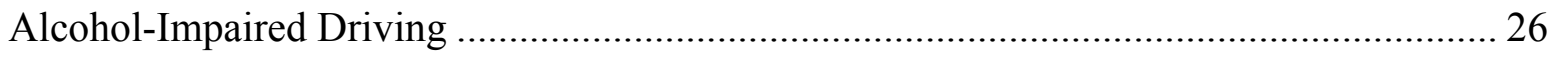

Figure 5.2. Cost-Effectiveness Ratios for 119 Anti-Drunk Driving Interventions .................... 27 



\section{Tables}

Table S.1. Evidence-Based Traffic Crash Interventions Analyzed in the Motor Vehicle

Prioritizing Interventions and Cost Calculator for States ................................................ xii

Table 3.1. Interventions Ranked Nationally by Cost-Effectiveness Ratio ................................ 12

Table 3.2. Top-Ranked Interventions, by Number of States Implementing ............................. 15

Table 4.1. Interventions That Could Be Funded with a 10-Percent Increase in State Funding

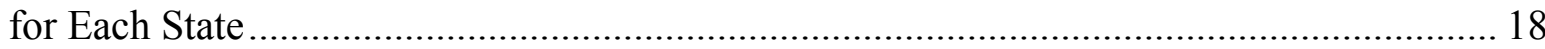

Table 4.2. Interventions That Could Be Funded with a 10-Percent Increase in Funding at the

National Level.

Table 5.1. Average Number of Drunk Driving-Related Fatalities, by Number of

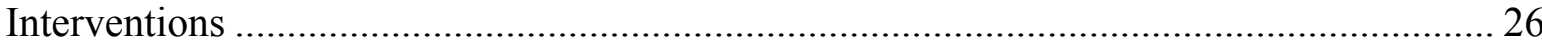

Table 5.2. Ten Instances with the Highest Cost-Effectiveness Ratios ...................................... 28

Table A.1. Cost Components and Subcomponents, by Intervention and Type of Cost .............. 36

Table A.2. Basis for Estimates of Injury and Death Reduction ............................................... 40

Table A.3. National Per-Injury and Per-Fatality Costs, in Dollars ......................................... 41 



\section{Summary}

Motor vehicle crashes are a leading cause of accidental death in the United States. In 2013, according to estimates, more than 32,700 Americans were killed and more than 2.3 million were injured in crashes (National Center for Statistics and Analysis, 2015). The direct and indirect costs of crashes are substantial. Recent research estimates that, in 2010, crash-related costswhich include a variety of costs borne by different groups, such as medical care, productivity, and travel delay — reached at least $\$ 242$ billion (Blincoe et al., 2015). Of course, these numbers do not fully capture the price of all consequences, including long-term harms to family and community quality of life.

A wide range of evidence-based policy and program interventions is available to states and communities to help prevent motor vehicle-related injuries and deaths. However, given limited resources, policymakers must prioritize and choose the interventions that will provide the greatest reduction in injuries and deaths for their implementation dollars. To do this, policymakers need information on the implementation costs and effects of interventions.

Toward this end, RAND researchers developed the Motor Vehicle Prioritizing Interventions and Cost Calculator for States (MV PICCS), which enables policymakers to compare 14 traffic crash-intervention policies and programs by cost and effectiveness by state. Analyses for individual states are available through the interactive online tool (www.cdc.gov/motorvehiclesafety/calculator/doc), as is full analytic documentation. This report uses cost-effectiveness estimates generated in MV PICCS to consider three policy questions from a national perspective:

- What are the effects of implementing the most cost-effective interventions?

- What is the most cost-effective way to allocate an increase in funding for interventions?

- Given this set of interventions, what is the most cost-effective way to reduce drunk driving?

\section{How Cost-Effective Are the Interventions from the Motor Vehicle Prioritizing Interventions and Cost Calculator for States?}

We selected the 14 interventions considered in MV PICCS on the basis of four criteria: They are interventions meant to change driver or passenger behavior (as opposed to changes to roadway or vehicle engineering); they can be implemented (or influenced) by states; they are demonstrated to be effective; and they are not already in widespread use. Table S.1 briefly describes the 14 interventions selected on this basis. 


\section{Table S.1. Evidence-Based Traffic Crash Interventions Analyzed in the Motor Vehicle Prioritizing}

Interventions and Cost Calculator for States

\begin{tabular}{|c|c|}
\hline Intervention & Description \\
\hline Automated red-light enforcement & $\begin{array}{l}\text { Cameras capture images of vehicles whose drivers fail to stop for red lights. } \\
\text { Commonly called red-light cameras, these are used primarily at intersections. } \\
\text { Tickets are sent to offenders by mail. }\end{array}$ \\
\hline $\begin{array}{l}\text { Automated speed-camera } \\
\text { enforcement }\end{array}$ & $\begin{array}{l}\text { Cameras capture images of vehicles whose drivers are driving in excess of posted } \\
\text { speed limits. Mobile speed cameras are often used to cover multiple road } \\
\text { segments. }\end{array}$ \\
\hline Alcohol ignition interlock & $\begin{array}{l}\text { Often called ignition interlocks, these devices prevent a vehicle from starting until } \\
\text { the driver has blown into a tube to prove sobriety. }\end{array}$ \\
\hline Sobriety checkpoints & $\begin{array}{l}\text { At a specific location, teams of police officers stop cars to check whether drivers } \\
\text { are intoxicated. }\end{array}$ \\
\hline Saturation patrols & $\begin{array}{l}\text { Police patrol selected locations, looking for suspicious driving behavior in an } \\
\text { attempt to identify alcohol-impaired drivers. }\end{array}$ \\
\hline Bicycle helmet laws & $\begin{array}{l}\text { These laws mandate that children who ride bicycles wear helmets to reduce the } \\
\text { likelihood of trauma to the head and related consequences. }\end{array}$ \\
\hline Universal motorcycle helmet laws & $\begin{array}{l}\text { This law requires all motorcyclists, regardless of age or experience level, to wear } \\
\text { a helmet that meets U.S. Department of Transportation safety standards. }\end{array}$ \\
\hline $\begin{array}{l}\text { Primary enforcement of seat } \\
\text { belt-use laws }\end{array}$ & $\begin{array}{l}\text { States with seat belt laws vary in their enforcement; a primary law allows police to } \\
\text { ticket offenders exclusively for not wearing seat belts. }\end{array}$ \\
\hline $\begin{array}{l}\text { High-visibility enforcement for } \\
\text { seat belts and child restraint and } \\
\text { booster seat laws }\end{array}$ & $\begin{array}{l}\text { This policy combines the intense enforcement of safety devises over a fixed } \\
\text { period with a publicity campaign. }\end{array}$ \\
\hline License plate impoundment & $\begin{array}{l}\text { This intervention requires a driver who has been convicted of DWI to surrender } \\
\text { the vehicle's license plate, which is either impounded or destroyed. In some } \\
\text { jurisdictions, the officer places a sticker on the license plate to indicate that it is } \\
\text { invalid. }\end{array}$ \\
\hline $\begin{array}{l}\text { Limits on DWI diversion and plea } \\
\text { agreements }\end{array}$ & $\begin{array}{l}\text { These rules prevent DWI arrestees from diverting cases (i.e., moving them out of } \\
\text { the judicial system) or pleading out of charges. }\end{array}$ \\
\hline Vehicle impoundment & $\begin{array}{l}\text { This intervention requires that a DWI offender's vehicle be confiscated for a period } \\
\text { of time, after which the offender either reclaims or surrenders his or her vehicle. }\end{array}$ \\
\hline $\begin{array}{l}\text { In-person license renewal for } \\
\text { older drivers }\end{array}$ & $\begin{array}{l}\text { This intervention requires any driver over age } 70 \text { to renew his or her driver's } \\
\text { license in person at a department of motor vehicles, instead of using mail-in or } \\
\text { online renewal. }\end{array}$ \\
\hline $\begin{array}{l}\text { Higher fines for seat belt-use } \\
\text { violations }\end{array}$ & $\begin{array}{l}\text { This intervention adds } \$ 75 \text { to a state's existing fine, which represents a significant } \\
\text { increase over existing seat belt fines in most states. }\end{array}$ \\
\hline
\end{tabular}

NOTE: DWI = driving while intoxicated.

Costs are defined in several ways for the tool, but the questions addressed in this report use only costs that the state bears to implement the interventions (such as police time). These are estimated based on nine cost components, most of which include specific subcomponents. The overall cost of each intervention is the sum of one or more components. We assume that some subcomponents remain constant between states, and we scale others for each state based on such factors as wage rates for state government employees and population size. 
Effectiveness is defined in two ways. First, we define it as the percentage of injuries and deaths that could be prevented when an intervention is implemented, for a specific crash type (for example, we found that alcohol interlocks reduce, by 24 percent, deaths that occur in crashes in which the driver has a previous DWI charge). We estimate the reduction in injuries or deaths of each intervention based on the best available study or meta-analysis of each one and develop estimates based on the number of vehicle crash deaths in that state for that particular crash type.

Second, we translate effectiveness into monetary terms based on the estimated value of saving a life or preventing an injury. We use existing literature to estimate the values for individual states, based on nine categories (such as medical costs).

With these figures, we develop a cost-effectiveness estimate for each intervention in each state-714 in all (14 interventions in 51 states). ${ }^{1}$ We then take some of these out of consideration, for two reasons. First, we eliminated three interventions from the national analysis presented here - two (saturation patrols and high-visibility enforcement) because we did not find reliable information on where they are already implemented, and one (increased seat belt fines) because the implementation cost is zero, based on the definition above. Second, we removed those interventions that are already implemented in individual states. Removing these interventions leaves 298 interventions across the 51 states for analysis. The cost-effectiveness of these 298 interventions varies from a high of 390 to 1 (we calculate these ratios with a denominator of 1 , so, hereafter, we use the numerator only) to less than 1 (which means that the intervention costs more than the benefits it produces). Overall, the full suite of these 298 interventions has a cost-effectiveness ratio of 6.8.

\section{A National Approach to Crash-Reduction Interventions Is Most Cost- Effective, but Not All States Benefit Equally}

For the first policy question, "What are the effects of implementing the most cost-effective interventions?" we develop a cost-effectiveness estimate of each intervention at a national level by summing the costs and benefits of the intervention in all states where is it not currently implemented. The cost-effectiveness of these individual interventions ranges from 130 for alcohol interlocks to 0.8 for limits on diversion and plea agreements. We also identify the most cost-effective intervention in each state. If all remaining states implemented the top three national interventions, 1,219 fatalities would be prevented for a cost to the state of approximately $\$ 55$ million. Universal motorcycle helmet laws alone would prevent 745 fatalities and cost $\$ 41$ million to implement. Implementing the most cost-effective intervention in each state would prevent 928 fatalities and cost about $\$ 60$ million. The national approach is more cost-effective, in

\footnotetext{
${ }^{1}$ Although the District of Columbia is not a state, in our analysis, we treat it the same as the 50 states. Therefore, for ease of reading, we refer to 51 states rather than 50 states and the District of Columbia.
} 
that more fatalities are prevented at a lower cost, but does not spread the reduction in fatalities across all states.

\section{Implementing the Most Cost-Effective Interventions Is the Best Way to Spend Additional Funding, but Not All States Will Benefit Equally}

For the second policy question, "What is the most cost-effective way to allocate an increase in funding for interventions?" we assume a 10-percent increase in federal funding to states (approximately $\$ 57.9$ million divided among the 51 states) to implement additional interventions and compare two ways to allocate this increase. The first is to increase each state's individual allocation by 10 percent and implement those interventions that are most cost-effective within that state. The second is to take the same $\$ 57.9$ million and spend it on the most cost-effective interventions, regardless of state. We do this by starting with the most cost-effective of the 298 interventions and working down the list until we have spent \$57.9 million. The first approach spends only $\$ 28.4$ million because many states cannot use the full allotment; many interventions exceed the 10-percent increase. This would save 660 lives in 47 states. The second approach would save 1,302 lives using the majority of the available funding (\$56.9 million) in 44 states. Although this approach is more cost-effective than giving each state a 10-percent increase in funding, it does not spread the benefit of reduced fatalities across as many states. These results suggest that, if additional funding were available at the national level to implement motor vehicle-related injury-prevention interventions, the most cost-effective way to allocate the funds would be to target the funding to the most cost-effective interventions regardless of state.

\section{The Most Cost-Effective Way to Reduce Driving-While-Intoxicated Deaths and Injuries Is to Implement the Most Cost-Effective Interventions, Regardless of State}

The third policy question is, "Given this set of interventions, what is the most cost-effective way to reduce drunk driving?" Using five interventions ${ }^{2}$ that target DWI specifically, we look at the cost-effectiveness ratios across all states. There are 255 possible intervention-state combinations (51 states times five interventions), and excluding those that are already in use leaves 119. Ten of these have cost-effectiveness ratios exceeding 100; if just these ten were implemented, they would save 170 lives in ten states at a cost of \$2.1 million. In comparison, if we implemented all 119 interventions in the states where they are not in place, the nation stands to save 1,182 lives at a cost of $\$ 764$ million. The country can save 14 percent of the fatalities with less than 0.5 percent the cost.

\footnotetext{
2 This analysis excludes saturation patrols; see "How Cost-Effective Are Interventions from the Motor Vehicle Prioritizing Interventions and Cost Calculator for States" at the beginning of this summary for explanation.
} 


\section{The Analysis Requires Assumptions and Has Limitations}

As far as we are aware, this is the first effort to estimate the implementation costs across a broad array of interventions and to translate these costs to the state level according to a specific state's demographics and traffic crash profile. However, we also acknowledge that there are important limitations to this analysis:

- The analysis is limited to $\mathbf{1 4}$ interventions. The tool does not include every possible intervention because of the criteria we used to select them. The tool cannot compare engineering-based interventions, which would have been extremely difficult to assess at the state level, with behavioral ones, and it omits others for which the evidence is still conflicting.

- We base the analyses on many assumptions. Various assumptions are needed to generate these estimates. We note a few examples here. First, the cost-effectiveness estimates reflect assumptions about the level and characteristics (e.g., how much enforcement is done and whether there was a publicity campaign) of implementation of the successful intervention. As a specific example, we estimated the number of cameras for each state's red-light and automated speed-camera enforcement. Second, the effectiveness estimates from the literature are based on conditions in a specific jurisdiction, which might not reflect the conditions in others. Third, in many cases, there was no evidence for a specific parameter (e.g., an intervention's effect on crash-related injuries), and we had to make assumptions. For example, effectiveness estimates for injuries were not available for most interventions, so, in the absence of more-specific information, we assumed that the reduction was the same as for fatality reductions. Finally, we used data for scaling by states from national databases, which we assumed accurately reflected conditions across states. We have tried to be very transparent about the assumptions made, and a prior report (Ringel et al., forthcoming) documents them. However, because of these assumptions, the estimates presented here should be considered approximations.

- We do not continually update the tool. We produced a tool that was based on the best available data at the time of the research. However, we have not updated two key sets of data: the number of fatalities by type per state and the implementation status of each intervention in each state. If, for example, deaths in vehicle crashes decline considerably in some states, the tool's estimates of lives saved will be too large.

For further details about all of the assumptions, as well as all the data sources, see the project documentation (Ringel et al., forthcoming).

Despite these limitations, we believe that the analyses can be of great use to state policymakers. We mean for the estimates to give policymakers a sense of the relative costs and effects of the different interventions under consideration. 



\section{Acknowledgments}

This project could not have taken place without the support and cooperation of CDC officials and staff. Erin K. Sauber-Schatz, our main contact, kept us on track, answered every question patiently, and provided extremely good advice. Ann M. Dellinger ensured that the project got under way as planned and provided oversight as needed. Jahlani Akil helped us navigate the process of applying for Office of Management and Budget approval for our interviews. Angela Salazar, Karrianna Turner-Marshall, and Leanna Fox assisted us with a variety of administrative procedures. Jessica Burke, Melvin Crum, and Kevin Webb helped us understand the technical requirements for programming the website to be compatible with CDC infrastructure and transferring it to CDC.

We also thank the Robert Wood Johnson Foundation for its support of additional work that allowed us to expand the tool and produce the specific analyses described in this report.

We thank the current and former RAND staff who contributed to the development of the tool, as well as this report. Johanna Zmud led much of the transportation work, Kathryn Connor developed the overall cost structure, Andrés Villaveces developed some of the cost models, and David Powell developed the estimates of effectiveness. Brian G. Chow and Gregory S. Jones developed the concepts for the tool, and Adrian Montero, Tina Panis, and Paul Ng programmed it. Christina Y. Huang conducted background research on costs and effectiveness, and Chaoling Feng helped compile the lists of interventions by state. Kate Giglio helped develop some key themes and how to visualize them, and Tanya Maiboroda designed the graphics. Andria Tyner, Joanna Mahoney, and Stephanie Lonsinger assisted with preparing the reference section and fact sheets, and Sounia Johnson helped collate data.

In addition, we thank Robyn Robertson of the Traffic Injury Research Foundation and James M. Anderson and Christopher Skeels of RAND for their thoughtful and constructive reviews of the project documentation and tool. Their input improved the final product significantly. Jurek Grabowski, director of research for the AAA Foundation for Traffic Safety, also made helpful comments on this report. 



\section{Abbreviations}

BAC blood alcohol concentration

CDC Centers for Disease Control and Prevention

CIOT Click It or Ticket

DMV department of motor vehicles

DWI driving while intoxicated

FARS Fatality Analysis Reporting System

MV PICCS Motor Vehicle Prioritizing Interventions and Cost Calculator for States

NHTSA National Highway Traffic Safety Administration 



\section{Chapter One. Introduction}

Globally, motor vehicle crashes are the eighth-leading cause of death for all ages and the leading cause of death for people ages 15 to 29 (World Health Organization, 2013). In recognition of this, in 2011, the World Health Organization called for a Decade of Action for Road Safety from 2011 to 2020 (World Health Organization, 2011). The problem is just as acute in the United States; in 2013, more than 32,700 people were killed and more than 2.3 million were injured in motor vehicle crashes (National Center for Statistics and Analysis, 2015). The direct and indirect economic costs associated with these crashes are substantial, estimated to be \$242 billion in 2010 (Blincoe et al., 2015).

Fortunately, a wide range of evidence-based interventions, including both policies and programs, can help prevent motor vehicle-related injuries. As such, the Centers for Disease Control and Prevention (CDC) has designated preventing motor vehicle-related injuries to be a "winnable battle." CDC's winnable battles are public health priorities with large-scale impact on health and with known, effective strategies to address them (CDC, 2014).

Given limited resources for implementing interventions, policymakers must prioritize interventions and choose those that will yield the greatest reduction in injuries and deaths for their implementation dollars. To accomplish this prioritization, policymakers require information on the costs and effects of interventions. Although considerable evaluation work has identified evidence-based motor vehicle-related injury-prevention interventions and estimated the costs of motor vehicle-related injuries and deaths in the United States, little has been done to identify the levels of economic resources needed to implement these interventions. Consequently, policymakers cannot fully assess the costs and effects of different interventions and select the most cost-effective ones.

In a series of projects funded by CDC and the Robert Wood Johnson Foundation, RAND researchers have developed state-level cost-effectiveness estimates to assist states in making evidence-based resource-allocation decisions relating to the implementation of effective motor vehicle-related injury-prevention interventions. The analyses are available through an interactive online tool, the Motor Vehicle Prioritizing Interventions and Cost Calculator for States (MV PICCS), that states can use to assess state-specific costs and effects of different interventions and to select interventions that are most effective for a given implementation budget (www.cdc.gov/motorvehiclesafety/calculator/doc). 
This report builds on these state-level analyses, combining the estimates in different ways to consider a set of policy questions from a national perspective. In the following chapters, we first provide a high-level overview of the approach used to generate the cost-effectiveness estimates and then consider three national policy questions:

- What are the effects of implementing the most cost-effective interventions?

- What is the most cost-effective way to allocate an increase in funding for interventions?

- Given this set of interventions, what is the most cost-effective way to reduce drunkdriving recidivism?

Finally, we summarize the findings, offer recommendations, and consider next steps.

Many challenges come with developing the cost and effectiveness estimates that underlie these analyses. In particular, we needed to make numerous assumptions to generate these estimates. We detail these assumptions elsewhere (Ringel et al., forthcoming). For example, the effectiveness estimates from the literature are typically associated with a particular jurisdiction and reflect the effect of the intervention as implemented there. We have tried to reflect that in our calculations of implementation costs. However, the literature does not always provide sufficient detail to do this, so we must make some assumptions about how an intervention was implemented to build the estimate. Moreover, the cost-effectiveness estimates based on these assumptions reflect the level and characteristics (e.g., how much enforcement is done and whether there was a publicity campaign) of implementation of the successful intervention. If the intervention is not implemented at the same level (e.g., not as much enforcement effort or publicity), the estimated costs and effects reported in MV PICCS will not be a good match.

The estimates presented here should be considered approximations. They are meant to give policymakers a sense of the relative costs and effects of the different interventions under consideration. Other costs and benefits not captured in our analysis might also be considered (e.g., the improved employment or quality of life among people who are deterred from driving while drunk, effects on civil liberties, or political issues that make some interventions more feasible than others). In essence, the estimates are intended to be one category of information that can inform the larger policy debate. 


\section{Chapter Two. Approach}

In this chapter, we summarize the steps in the development and analysis of our costeffectiveness estimates. For more-detailed information on the sources of cost and benefit information and the assumptions and analyses that generate the cost-effectiveness estimates, please see the full documentation (Ringel et al., forthcoming).

\section{Intervention Selection}

We based our selection of interventions on four criteria. Each intervention had to meet all four of these criteria:

- intended to change driver or passenger behavior (as opposed to changes to roadway or vehicle engineering)

- implementable at the state level (or affected by state policy)

- demonstrated to be highly effective

- not already in widespread use (this generally meant that no more than 30 or so states had implemented the intervention).

Thus, the goal was to focus on interventions that would bring the greatest possible effectiveness from implementation because there is greater potential for states to adopt them. We assumed that the majority of the gains from widespread interventions, such as changes to the blood alcohol limit for enforcing drunk driving laws, have already been realized. We used information about effectiveness and current use from the National Highway Traffic Safety Administration (NHTSA) report Countermeasures That Work (University of North Carolina Highway Safety Research Center, 2011). Ultimately, 14 interventions met these criteria:

- Automated red-light enforcement: Automated red-light enforcement, more commonly called red-light cameras, is used to capture images of vehicles whose drivers fail to stop for red lights. Tickets are generally sent to offenders by mail.

- Automated speed-camera enforcement: Similarly, automated speed-camera enforcement, often called speed cameras, capture images of vehicles whose drivers are driving in excess of the posted speed limit. Unlike red-light cameras, which are deployed only at intersections, mobile speed cameras are often used to cover multiple road segments.

- Alcohol interlocks: Alcohol interlocks, also called ignition interlocks, are devices that prevent a vehicle from starting until the driver has blown into a tube, which determines that their blood alcohol concentration (BAC) is below the allowable level set by the state (0.02 in most jurisdictions). This intervention calls for interlocks to be installed on the vehicles of convicted repeat driving-while-intoxicated (DWI) offenders, as well as highBAC and first offenders, depending on state legislation.

- Sobriety checkpoints: At a sobriety checkpoint, teams of police officers stop cars at a specific location to check drivers for alcohol levels. States generally publicize such 
events to discourage drivers from drinking, particularly during times when drunk driving is more common than usual (such as holiday weekends).

- Saturation patrols: Saturation patrols consist of an increased police presence in selected locations where they patrol the area looking for suspicious driving behavior in an attempt to identify alcohol-impaired drivers. In contrast to sobriety checkpoints, saturation patrols do not stop every vehicle.

- Bicycle helmet laws: Bicycle helmet laws mandate that children who ride bicycles wear helmets, to reduce the likelihood of trauma to the head and its related consequences.

- Universal motorcycle helmet laws: This law requires every motorcyclist, regardless of age or experience level, to wear a helmet that meets safety standards set by the U.S. Department of Transportation. These laws differ from partial helmet laws, which typically apply only to riders below a certain age.

- Primary seat belt-use laws: States with seat belt laws vary in their enforcement. A primary law allows police to ticket offenders exclusively for not wearing seat belts. A secondary law allows police to write a ticket for not wearing a seat belt only if the driver has been pulled over for a different offense.

- High-visibility enforcement for seat belts and child restraint and booster seat laws: Highvisibility enforcement is a technique that combines intense enforcement over a fixed period (for example, one or two weeks) with a publicity campaign. A campaign focused on restraint use generally includes all forms of restraints: seat belts, child safety seats, and booster seats.

- License plate impoundment: This intervention requires a driver who has been convicted of DWI to surrender the vehicle's license plate, which is either impounded or destroyed. In some jurisdictions, the license plate is not physically removed; rather, the officer places a sticker on the license plate to indicate that it is invalid. The stickers are designed so that, if people try to remove them, they leave a visible pattern on the plate.

- Limits on diversion and plea agreements: Although all states have penalties for DWI, many states have additional programs that allow some offenders to be diverted out of the normal procedures or to plead guilty to a lesser offense and receive a lighter sanction. These programs are most often targeted at first-time offenders, with the goal of reducing the DWI caseload by diverting people who are thought to be unlikely to reoffend.

- Vehicle impoundment: This intervention results in vehicles of DWI offenders being confiscated for a period of time and stored in a public impound lot. An offender can either reclaim or surrender the vehicle when the impoundment period ends.

- In-person license renewal for older drivers: This intervention requires any driver over age 70 to renew his or her driver's license in person at a department of motor vehicles (DMV), instead of using mail-in or online renewal.

- Higher fines for seat belt-use violations: This intervention adds \$75 to a state's existing fine, which represents a significant increase over existing seat belt fines in most states.

\section{Implementation Cost Estimation}

In the tool, the costs associated with these interventions fall into one of four categories: costs that the state bears to implement the intervention (such as the cost of police time), costs that individuals pay to the state (such as a seat belt fine), costs that individuals bear but do not pay to 
the state (such as legal representation), and costs that individuals bear to comply with the law (such as a motorcycle helmet purchase). In the cost-effectiveness analyses for this report, we use only the first category, costs that the state bears.

We build the estimated costs of the interventions from a set of cost components. The costestimating structure has nine components, ${ }^{3}$ divided into multiple subcomponents. The nine cost components are

- publicity costs

- police and highway patrol time costs

- DMV staff time costs

- court-system costs

- equipment costs (acquisition, maintenance, and replacement)

- probation costs

- education program costs

- impoundment costs

- program management costs.

We combine cost components and subcomponents to create intervention-specific estimates. For most costs, we used multiple sources. We scaled some costs, such as the cost of staff time for state personnel (such as highway patrols and DMV staff), to each state based on wage rates provided by the Bureau of Labor Statistics (Bureau of Labor Statistics, 2012). For other cost components, the research team developed a "most common cost" that was used across all states, based on the range of costs that were documented. In some cases, we developed figures for cost estimates (such as the number of red-light and speed cameras) using count regression models. We amortized up-front costs, such as equipment, over five years. Table A.1 in the appendix outlines the cost components and associated values for each intervention. For additional detail on the costing methodology, please see Ringel et al., forthcoming.

The overall cost of an intervention is the sum of the cost components. The total cost for an intervention varies across states, depending on geographic size, population, wage rates, and other factors. Some cost components are fairly constant across states (e.g., program management), and others vary in relation to the geographic size and population of the state (e.g., police and highway patrol time costs, publicity costs, and equipment).

As a result, some interventions have fairly low costs across all states, while others have a high degree of variation. For example, the cost of bicycle helmet laws and license plate impoundment do not vary a great deal from state to state because relatively few cost components are involved. The cheapest intervention of all, increased seat belt fine, is considered to have a

\footnotetext{
${ }^{3}$ The project documentation refers to ten cost components; the tenth is fines and fees paid to the state. These are an important part of how the tool works because users can include these fines and fees-which essentially constitute revenue to the state - to see the extent to which they defray the costs of implementation. Essentially, this means that each intervention implemented in a state has two cost calculations - one including these fines and fees, and one without. For this cost-effectiveness analysis, we chose to use the second of these, the cost without any fines and fees, because states might not be able to use the revenue collected to implement additional interventions.
} 
cost of zero in every state because none of the nine cost components is required for implementation. So the cost-effectiveness ratio is always zero. ${ }^{4}$

Other interventions have a very wide variation in costs. Sobriety checkpoints and primary seat belt-use laws vary because a key element is the amount of police time to enforce the laws, which is, in turn, a function of the size of the state (both geography and population). Limits on diversion and plea agreements costs also vary, in part because of the use of DWI arrest statistics to develop the estimate of how many people who might otherwise use a diversion program or plea bargain down a DWI charge would instead go through the judicial system. These numbers vary widely from state to state. ${ }^{5}$

A final caveat about costs is that not all interventions are either implemented or not. Speed and red-light cameras, for example, could be placed in a few jurisdictions but not throughout a state. However, for our purposes, we have had to make assumptions about the intensity of the implementation to develop a single cost per state. We detail these assumptions for each intervention in the project documentation (Ringel et al., forthcoming). MV PICCS users can change the implementation costs through sensitivity analysis.

\section{Literature Review on Effectiveness}

Effectiveness is defined as the fatalities and injuries reduced by implementing a particular intervention. The research team developed two types of information: the actual number of anticipated lives saved and injuries prevented and a monetized value of those two things.

There is a substantial literature estimating the effectiveness of motor vehicle-related injuryprevention estimates. We build off that literature, taking effectiveness estimates from published articles and reports that document empirical studies of the effectiveness of interventions, generally on a before-and-after basis. These thus reflect real-world experience with not just the interventions but also compliance and enforcement (e.g., it is not assumed that all motorcycle riders will wear helmets after a helmet law is passed; rather, the estimate is based on studies of states that passed such laws). With one exception, the studies or meta-analyses that we used in developing these estimates looked at fatalities only (see Table A.2 in the appendix). The exception is sobriety checkpoints, for which there are distinct estimates in the literature. For this intervention, the effect on injuries is 20 percent and 8.1 percent for fatalities.

Lacking any other information, for all other interventions, we assumed that the effects on injuries were the same as those on fatalities. For example, the study we used to determine the

\footnotetext{
${ }^{4}$ Obviously, there are other costs associated with many of these interventions, such as the political cost (e.g., it could be difficult politically to increase an unpopular fine). However, lacking a sound methodology to monetize such an intangible cost, we did not include these.

${ }^{5}$ In particular, Alabama provided limited arrest information to the Federal Bureau of Investigation database that we used as the data source, so it shows far fewer DWI arrests than other states of similar size. Hawaii lacked any data for the year we used, so we used data from the previous year as a substitute.
} 
effect of primary seat belt-use laws found a 7-percent reduction in fatalities, so we assumed that injuries also declined by 7 percent. Probably the largest issue with this assumption is that certain interventions can turn fatalities into injuries; that is, a person whose life is saved by wearing a seatbelt might instead suffer an injury. But making accurate estimates of how often this happens and comparing those with the reductions in injuries themselves is seldom done in the literature. In addition, the difficulty with studying injuries is that they range widely in severity, from minor to permanently disabling. There is no information in the literature to support a more sophisticated estimate, so we made this simplifying assumption.

We also note that, for two DWI-related interventions, license plate impoundment and limits on diversion and plea agreements, we could not identify any studies with deaths or reductions in crashes as the metric, only reductions in recidivism. We recognize that a reduction in recidivism is probably higher than a reduction in actual crashes or deaths and thus represents a best-case estimate of reductions in injuries and deaths. However, given the dearth of studies in this area, we felt that this was the best assumption we could develop.

\section{Estimation of Benefits}

The research team used an existing protocol to determine the economic benefits of a life saved or an injury prevented (Blincoe et al., 2015), ${ }^{6}$ developed specifically to monetize the benefits from reducing crashes. The protocol includes nine categories for both fatalities and injuries, and the research team calculated a weighted average for injuries based on the relative frequencies of each injury severity type (Table A.3 in the appendix). Three categories were scaled at the state level: market productivity, household productivity, and medical expenditures. We based scaling on state-specific price adjustments employed by CDC's Web-based Injury Statistics Query and Reporting System cost-of-injury reports (CDC, 2015), computed using Council for Community and Economic Research cost-of-living index data (Council for Community and Economic Research, undated) and population data. For the other six, we used national estimates (updated to 2012 dollars). This provided a monetary value for each life saved or injury prevented specific to each state.

To create state-specific estimates of the value of lives saved and injuries avoided, we combined estimates of reductions in fatalities and injuries and the estimated monetized benefits. We scaled these reductions to each state, based on the number of injuries and fatalities associated with particular crash causes in 2010 (using the Fatality Analysis Reporting System [FARS] and General Estimates System for injuries) for that state (NHTSA, undated [a], undated [b]). (At the time we collected data for MV PICCS, 2010 was the most recent year available.) This scaling is needed because interventions address particular crash types (e.g., a universal motorcycle helmet

\footnotetext{
6 In May 2015, NHTSA reissued the Blincoe report (previously Blincoe et al., 2014) after errors were found in the initial analysis. We have updated our estimates accordingly.
} 
law is expected to reduce motorcycle fatalities), and the mix of crash types varies between states (e.g., Florida, California, and Texas have more motorcycle crashes than other states do).

The monetized value of a life saved or injury prevented, although scaled to each state, tends to be fairly similar across states. The variation in these values across states for a particular intervention is driven primarily by differences in the number of fatalities per category. For example, four states had no bicyclist deaths in 2010, and the District of Columbia had no deaths caused by a person with a previous DWI charge. So the benefits in these cases are zero because (happily) we cannot reduce deaths any further. Of course, this means that MV PICCS will be inaccurate if these are statistical flukes. If a state had an unusually high or low number of fatalities in 2010, the results might be skewed to some extent.

In addition, states with higher numbers of certain types of crashes will see greater benefits from the interventions that address those causes. The largest states, not surprisingly, have the highest number of fatalities - one-quarter of all traffic fatalities occur in Texas, California, and Florida. But states often experience certain fatality types disproportionately to their population size. Rural Wyoming and Montana have very high rates of alcohol-related deaths per 100,000 population. These differences mean that the benefits for some interventions in some states are unusually high or low.

\section{Cost-Effectiveness Estimates}

Using the state-specific estimates of implementation costs and benefits, we generated a costeffectiveness estimate for each of the 14 interventions in each state. This is the ratio of the total annual monetized benefit to the total annual implementation cost for each separate intervention. The higher the ratio of effectiveness to costs, the more cost-effective the intervention is.

The cost-effectiveness ratios vary from less than 1 to almost 400. Using the method above, the ratio cannot be less than 0 , and a ratio between 0 and 1 implies that the costs outweigh the benefits (that is, implementing the intervention would cost more than the benefits it would provide). The highest cost-effectiveness ratio in our data is for alcohol interlocks in Ohio at 390. A cost-effectiveness ratio of 390 indicates that the benefits exceed the costs 390 to 1 . The costeffectiveness estimates for a particular intervention vary across states because the implementation costs and benefits for each intervention differ between states based on their characteristics (e.g., geographic size or population). 


\section{Using the Estimates for National Policy Analysis}

The next three chapters look at different potential ways to best allocate funding to reduce crash-related deaths and injuries, based on the set of cost-effectiveness estimates described above. The following two caveats apply:

- First, although MV PICCS includes cost-effectiveness estimates for all 14 interventions, the analyses conducted for this report exclude three. We assume increased seat belt fines to have zero cost, so we cannot calculate a cost-effectiveness ratio. We could not definitely determine the presence or absence of two interventions, saturation patrols and high-visibility enforcement, in the states, so we have excluded these from comparisons as well.

- Second, we generated these estimates regardless of any information we collected on whether the interventions are already implemented in certain states. For the analyses included here, we remove from consideration those interventions that we believe to be already implemented. However, our information about which interventions are in use in which states might be outdated because we have not continuously updated them. In MV PICCS, however, the user can customize the analysis to include or exclude any of the 14 interventions.

The data that we used for these 11 interventions and where they are implemented produce 298 combinations of potential interventions by state that could be implemented. If all of these were implemented, they would cost almost $\$ 2.1$ billion, produce benefits of $\$ 14.2$ billion, and collectively save 3,939 lives and prevent 429,984 injuries. However, of these 298 combinations, 31 are not considered cost-effective; the ratio of costs to benefits is less than 1. Excluding these would lower the totals to 3,820 lives saved and 424,179 injuries prevented, while reducing costs to $\$ 1.6$ billion. The total benefit would decline slightly to $\$ 13.9$ billion.

Figure 2.1 shows all 298 combinations and the relationship between the number of lives potentially saved and the cost-effectiveness ratio. Ideally, we would want to implement the interventions in the upper right quadrant because these would both be highly cost-effective and save the most lives. But, as Figure 2.1 shows, no interventions fall into that quadrant; there is some trade-off between a high cost-effectiveness ratio and the greatest number of lives saved. 
Figure 2.1. Scatterplot of Lives Saved and Cost-Effectiveness Ratio for 298 Combinations of Interventions in States

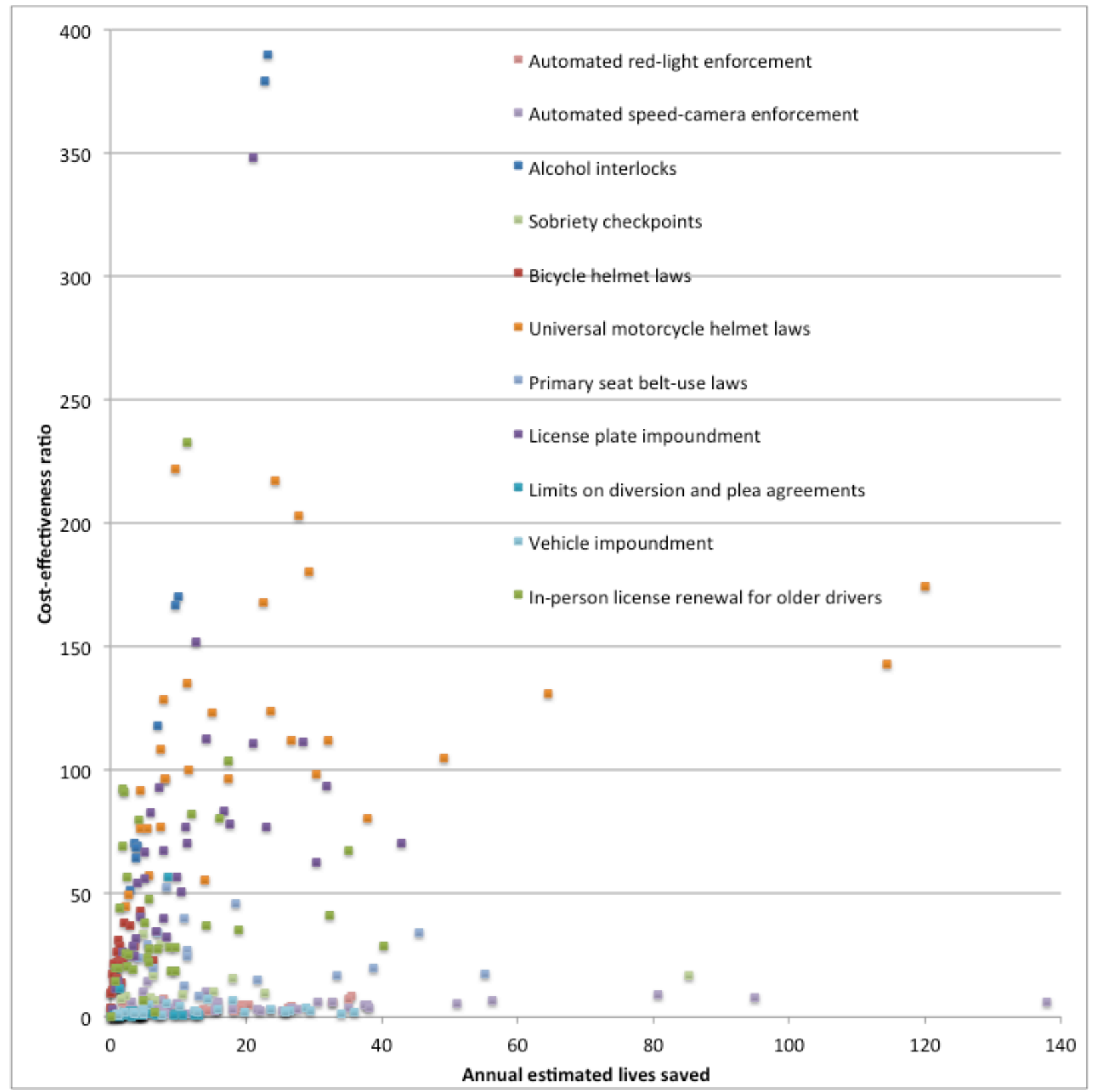

The following three chapters discuss specific ways to achieve some of these benefits. In particular, we focus on three policy questions:

- What are the effects of implementing the most cost-effective interventions?

- What is the most cost-effective way to allocate an increase in funding for interventions?

- Given the five DWI interventions analyzed, what is the most cost-effective way to reduce drunk driving? 


\section{Chapter Three. What Are the Effects of Implementing the Most Cost-Effective Interventions?}

In this chapter, we use the data underlying MV PICCS to identify the most cost-effective interventions nationally, as well as for each state. We then estimate the expected costs and benefits associated with different approaches for selecting which interventions to implement. The first approach takes a national perspective, selecting interventions to implement in all states. The second approach is tailored to the state level, selecting the most cost-effective intervention for each state.

\section{National-Level Approach}

For our national-level approach, we aggregate the costs and benefits across states for each intervention, excluding the states where the intervention is already in place. We then create a national cost-effectiveness estimate for each intervention and rank them from high to low. For state-level analyses, we ranked the interventions within a state. We define the costs of the intervention as the costs to the state only; we do not include fines and fees that could be used to offset costs.

On a national basis, the top three countermeasures are alcohol interlocks, universal motorcycle helmet laws, and license plate impoundment. By this, we mean that these interventions save the most lives relative to the costs of implementation. Nationally, alcohol interlocks would save 93 lives and prevent 3,352 injuries in the first year of implementation for just $\$ 1.4$ million in implementation costs. Universal motorcycle helmet laws could prevent 745 fatalities and 197,019 injuries for just over $\$ 41$ million, and license plate impoundment would save an additional 382 lives for $\$ 12.4$ million. The full list of interventions is shown in Table 3.1. 
Table 3.1. Interventions Ranked Nationally by Cost-Effectiveness Ratio

\begin{tabular}{|c|c|c|c|c|c|c|}
\hline Intervention & $\begin{array}{l}\text { Number of States } \\
\text { Without This } \\
\text { Intervention }\end{array}$ & $\begin{array}{l}\text { Lives } \\
\text { Saved }\end{array}$ & $\begin{array}{l}\text { Injuries } \\
\text { Prevented }\end{array}$ & Cost (\$) & Benefit (\$) & $\begin{array}{l}\text { Cost- } \\
\text { Effectiveness } \\
\text { Ratio }\end{array}$ \\
\hline Alcohol interlocks & 12 & 93 & 3,352 & $1,426,000$ & $185,348,000$ & 129.9 \\
\hline $\begin{array}{l}\text { Universal } \\
\text { motorcycle helmet } \\
\text { laws }\end{array}$ & 30 & 745 & 197,019 & $41,000,000$ & $5,020,486,000$ & 122.4 \\
\hline $\begin{array}{l}\text { License plate } \\
\text { impoundment }\end{array}$ & 34 & 382 & 13,814 & $12,397,000$ & $823,687,000$ & 66.4 \\
\hline $\begin{array}{l}\text { In-person license } \\
\text { renewal for older } \\
\text { drivers }\end{array}$ & 35 & 307 & 28,096 & $41,220,000$ & $1,012,367,000$ & 24.5 \\
\hline $\begin{array}{l}\text { Bicycle helmet } \\
\text { laws }\end{array}$ & 26 & 38 & 6,587 & $7,998,000$ & $184,965,000$ & 23.1 \\
\hline $\begin{array}{l}\text { Primary seat belt- } \\
\text { use laws }\end{array}$ & 16 & 302 & 31,876 & $53,793,000$ & $1,064,900,000$ & 19.8 \\
\hline $\begin{array}{l}\text { Sobriety } \\
\text { checkpoints }\end{array}$ & 12 & 187 & 16,680 & $46,052,000$ & $601,760,000$ & 13.1 \\
\hline $\begin{array}{l}\text { Automated speed- } \\
\text { camera } \\
\text { enforcement }\end{array}$ & 42 & 1,006 & 83,128 & $781,170,000$ & $3,113,150,000$ & 4.0 \\
\hline $\begin{array}{l}\text { Automated red- } \\
\text { light enforcement }\end{array}$ & 30 & 358 & 30,755 & $381,503,000$ & $1,085,343,000$ & 2.8 \\
\hline $\begin{array}{l}\text { Vehicle } \\
\text { impoundment }\end{array}$ & 27 & 382 & 13,816 & $340,069,000$ & $796,504,000$ & 2.3 \\
\hline $\begin{array}{l}\text { Limits on diversion } \\
\text { and plea } \\
\text { agreements }\end{array}$ & 34 & 139 & 5,031 & $363,741,000$ & $293,935,000$ & 0.8 \\
\hline Total & & 3,939 & 430,153 & $2,070,370,000$ & $14,182,445,000$ & 6.8 \\
\hline
\end{tabular}

NOTE: We have rounded the numbers of lives saved and injuries prevented to the nearest decimal place. We have rounded the amounts of benefits and costs to the nearest 1,000. The totals and cost-effectiveness ratios are based on the underlying numbers, so some slight inconsistencies are due to this rounding.

As Table 3.1 shows, the interventions fall off quite rapidly in terms of their costeffectiveness. The last one, limits on diversion and plea agreements, would not be cost-effective if implemented in all states. ${ }^{7}$ Four other interventions - in-person license renewal for older drivers, speed cameras, red-light cameras, and vehicle impoundment — are not cost-effective in any state.

As an additional comparison, Figure 3.1 graphs these same cost-effectiveness ratios on a cumulative basis. The left-most data point, labeled in the x-axis as 1, represents the costeffectiveness ratio of alcohol interlocks. The second data point, 2 , is the cost-effectiveness ratio of alcohol interlocks plus universal motorcycle helmet laws (that is, we added the benefits of

${ }^{7}$ Limits on diversion and plea agreements would be cost-effective in 12 of the 34 states in which it is not already implemented. 
both together and divided by the costs of both). The data point labeled 11 is the average for all interventions, 6.8 .

Figure 3.1. Cumulative Cost-Effectiveness Ratios of the 11 Interventions

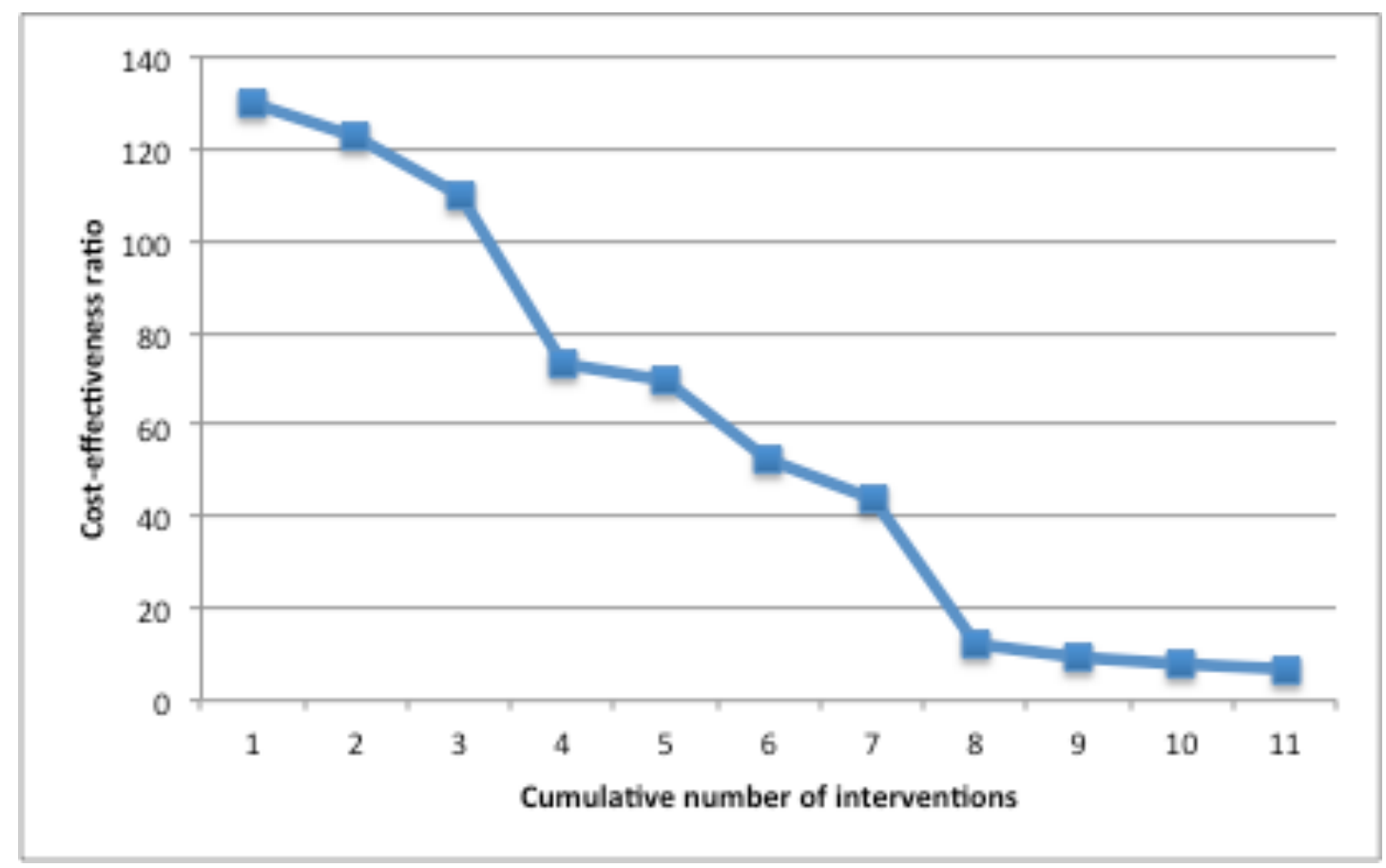

NOTE: The figure shows these cost-effectiveness ratios cumulatively. The left-most data point, labeled in the $x$-axis as 1 , represents the cost-effectiveness ratio of alcohol interlocks. The second data point, 2 , is the cost-effectiveness ratio of alcohol interlocks plus universal motorcycle helmet laws (that is, we added the benefits of both together and divided by the costs of both). The data point labeled 11 is the average for all interventions, 6.8.

\section{State-Level Approach}

Instead of implementing the same interventions across all states, the second approach we use looks within each state and selects the top-ranked intervention for that state to implement. The top-ranked intervention varies across states because of differences in characteristics and the set of interventions that are already in place (see Figure 3.2). According to our count, 30 states lack universal motorcycle helmet laws, and, in 24 of those states, universal motorcycle helmet laws would be the most cost-effective intervention. No other intervention ranked so high in terms of the proportion of states that would benefit from adoption. The state with the greatest benefit is Texas, which could potentially prevent 120 deaths and nearly 31,800 injuries in the first year after implementing this intervention. Across all 24 states where universal motorcycle helmet laws are ranked first, we estimate that 605 lives would be saved. An additional 140 lives would be saved in the other six states that do not currently have universal motorcycle helmet laws in place. 
Universal motorcycle helmet laws tend to rank high in cost-effectiveness for three reasons. First, they are relatively inexpensive to implement- the implementation costs consist largely of additional police time. Second, they are one of the most effective interventions in terms of saving lives, achieving a 29-percent reduction in motorcycle fatalities. Finally, states without universal motorcycle helmet laws benefit because they have higher ratios of motorcycle fatalities. Of the 15 states where motorcycle deaths accounted for 15 percent or more of all vehicle crash-related deaths (the national average is about 13.5 percent), only three have universal motorcycle helmet laws already.

The next intervention is license plate impoundment, which was ranked highest in 12 states. This intervention tends to be one of the least expensive (on average, $\$ 360,000$ in annual costs to the state) because it consists largely of DMV staff time, and it reduces fatalities caused by drivers with previous DWI arrests by 27 percent.

The third intervention is in-person license renewal for older drivers, the highest ranked in eight states. The intervention tends to be fairly inexpensive (on average, $\$ 1.2$ million to implement in states that do not already have this intervention). Although its average costeffectiveness ratio is only the fourth highest of all interventions (see Table 3.1), there is a wide range among states. In the District of Columbia, this is the only possible intervention to be implemented, and, in Maryland, it is the more cost-effective of two available.

The other interventions trail off quickly in terms of the number of states where they are considered the most effective (see Table 3.2). 
Figure 3.2. Top Intervention for Each State

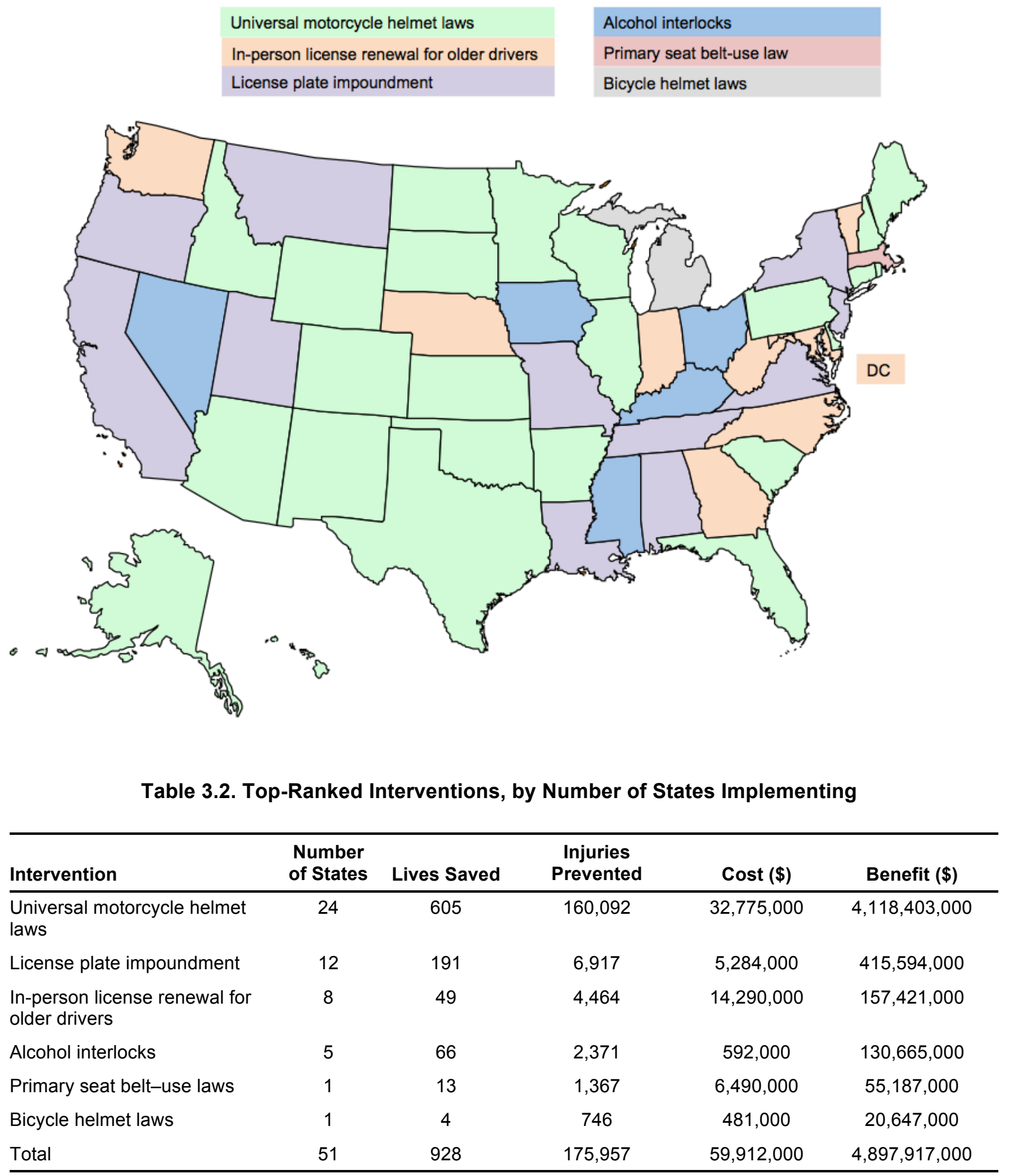

NOTE: We have rounded benefits and costs to the nearest 1,000 . 
Looking across the two approaches-implementing interventions that are most cost-effective nationally and implementing the interventions that are most cost-effective in each individual state - suggests that the national approach is more cost-effective. This is because the national approach focuses on implementing the most cost-effective interventions wherever they are not already in place. This generally provides a good return on limited traffic safety dollars because, with just two interventions, alcohol interlocks and universal motorcycle helmet laws, the interventions can save 838 lives and prevent just over 200,000 injuries at a total cost of about $\$ 42.5$ million. If, in contrast, each state implements the most cost-effective intervention in that state, they can save 928 lives for about $\$ 59.9$ million—a 25-percent increase in lives saved but a 50-percent increase in implementation costs.

The main reason that the state-based approach is less cost-effective overall is that it leads some states, where the most cost-effective interventions are already in place, to implement interventions with low cost-effectiveness ratios. Maryland is an extreme example of this because it has already implemented nine of the 11 interventions considered in this analysis. As a result, the most cost-effective intervention in Maryland is one in which the implementation costs exceed the expected benefits. This highlights that focusing on implementing the most cost-effective interventions regardless of location maximizes the reduction in deaths and injuries per dollar spent. 


\section{Chapter Four. What Is the Most Cost-Effective Way to Allocate an Increase in Funding for Interventions?}

As shown in Chapter Three, the interventions that are most cost-effective vary widely from state to state. In this chapter, we use data from MV PICCS to compare two ways of allocating additional traffic safety money to states: by providing it equally across states and by targeting the most cost-effective interventions regardless of location.

Each year, the federal government provides approximately $\$ 579$ million to states for traffic safety programs (Governors Highway Safety Association, undated). Our thought experiment begins with assuming that this amount increases by 10 percent, such that an additional $\$ 57.9$ million is available for the whole country. We can allocate this increase in two ways: increase each state's allocation by 10 percent, or spend the money where it is most effective, regardless of state. We assume that states continue to fund their existing traffic safety policies, and we use MV PICCS to calculate whether any additional interventions could be added in each state based on the costs of the interventions they do not currently have.

To assess the impact of increasing each state's allocation by 10 percent, we rank each intervention in each state by its cost-effectiveness ratio, using the rankings developed in Chapter Three. For each state, we calculate what a 10-percent increase in funding would be and assume that these funds would be available to the state for new interventions. The available funding ranged from about $\$ 325,000$ in New Hampshire to $\$ 7.9$ million in California, with an average of about $\$ 1.1$ million.

If the highest-ranked intervention would cost less to implement than the available funding, we assume that it could be implemented. For example, Alabama had about $\$ 815,000$ available, and its highest-ranked intervention, license plate impoundment, costs $\$ 118,000$ to implement under our assumptions. We assume that Alabama will implement this intervention and calculate that it still has about $\$ 697,000$ available to spend. We then look at the second-ranked intervention, limits on diversion and plea agreements, to see whether it can be implemented for less than the remaining funding. For each state, we go through this iterative process to identify the most cost-effective interventions that the state can afford. If the highest-ranked intervention costs more than the available funding, we go to the second-highest-ranked intervention, and so forth. We continue this process until none of the remaining interventions is affordable with the funds the state had available or until all interventions are implemented.

Table 4.1 shows the results of this analysis. These interventions collectively save 660 lives and prevent more than 46,500 injuries in 47 states. 
Table 4.1. Interventions That Could Be Funded with a 10-Percent Increase in State Funding for Each State

\begin{tabular}{|c|c|c|c|c|c|}
\hline Intervention & State & Lives Saved & $\begin{array}{l}\text { Injuries } \\
\text { Prevented }\end{array}$ & Cost (\$) & Benefit (\$) \\
\hline \multirow[t]{10}{*}{ Alcohol interlocks } & Idaho & 4 & 139 & 114,000 & $7,347,000$ \\
\hline & Indiana & 10 & 365 & 119,000 & $20,194,000$ \\
\hline & lowa & 10 & 347 & 118,000 & $19,755,000$ \\
\hline & Kentucky & 23 & 825 & 115,000 & $43,618,000$ \\
\hline & Maine & 4 & 148 & 119,000 & $8,265,000$ \\
\hline & Mississippi & 7 & 252 & 108,000 & $12,741,000$ \\
\hline & Nevada & 3 & 104 & 128,000 & $6,598,000$ \\
\hline & Ohio & 23 & 842 & 123,000 & $47,953,000$ \\
\hline & Rhode Island & 1 & 35 & 138,000 & $2,173,000$ \\
\hline & Vermont & 1 & 26 & 126,000 & $1,540,000$ \\
\hline \multirow{17}{*}{$\begin{array}{l}\text { Bicycle helmet } \\
\text { laws }\end{array}$} & Arizona & 3 & 489 & 358,000 & $13,247,000$ \\
\hline & Arkansas & 0 & 26 & 177,000 & 663,000 \\
\hline & Colorado & 1 & 206 & 286,000 & $6,179,000$ \\
\hline & Illinois & 4 & 618 & 634,000 & $18,340,000$ \\
\hline & Indiana & 2 & 335 & 348,000 & $9,024,000$ \\
\hline & Kansas & 0 & 26 & 182,000 & 722,000 \\
\hline & Kentucky & 1 & 180 & 239,000 & $4,735,000$ \\
\hline & Michigan & 4 & 746 & 481,000 & $20,647,000$ \\
\hline & Minnesota & 1 & 232 & 294,000 & $6,930,000$ \\
\hline & Mississippi & 1 & 103 & 185,000 & $2,640,000$ \\
\hline & Missouri & 1 & 180 & 314,000 & $4,939,000$ \\
\hline & Nebraska & 0 & 51 & 133,000 & $1,443,000$ \\
\hline & Ohio & 2 & 283 & 556,000 & $7,820,000$ \\
\hline & Oklahoma & 1 & 232 & 222,000 & $6,342,000$ \\
\hline & South Carolina & 2 & 360 & 251,000 & $9,543,000$ \\
\hline & Texas & 6 & 1,081 & $1,360,000$ & $30,740,000$ \\
\hline & Wisconsin & 1 & 232 & 298,000 & $6,569,000$ \\
\hline \multirow{8}{*}{$\begin{array}{l}\text { In-person license } \\
\text { renewal for older } \\
\text { drivers }\end{array}$} & California & 35 & 3,180 & $1,815,000$ & $122,650,000$ \\
\hline & Georgia & 17 & 1,586 & 520,000 & $53,969,000$ \\
\hline & Indiana & 11 & 1,022 & 148,000 & $34,458,000$ \\
\hline & lowa & 5 & 458 & 412,000 & $15,773,000$ \\
\hline & Nebraska & 3 & 237 & 332,000 & $8,361,000$ \\
\hline & New Hampshire & 2 & 172 & 97,000 & $6,705,000$ \\
\hline & North Carolina & 16 & 1,455 & 620,000 & $49,721,000$ \\
\hline & Rhode Island & 1 & 74 & 138,000 & $2,769,000$ \\
\hline
\end{tabular}




\begin{tabular}{|c|c|c|c|c|c|}
\hline Intervention & State & Lives Saved & $\begin{array}{l}\text { Injuries } \\
\text { Prevented }\end{array}$ & Cost (\$) & Benefit (\$) \\
\hline & South Dakota & 2 & 180 & 67,000 & $6,120,000$ \\
\hline & Tennessee & 12 & 1,095 & 449,000 & $36,836,000$ \\
\hline & Utah & 2 & 221 & 127,000 & $7,188,000$ \\
\hline & Vermont & 1 & 123 & 99,000 & $4,386,000$ \\
\hline & Virginia & 10 & 875 & $1,190,000$ & $33,163,000$ \\
\hline & Washington & 6 & 523 & 422,000 & $20,024,000$ \\
\hline & West Virginia & 4 & 376 & 149,000 & $11,917,000$ \\
\hline \multirow{29}{*}{$\begin{array}{l}\text { License plate } \\
\text { impoundment }\end{array}$} & Alabama & 21 & 762 & 118,000 & $41,205,000$ \\
\hline & Alaska & 0 & 10 & 205,000 & 627,000 \\
\hline & California & 43 & 1,553 & $1,432,000$ & $100,424,000$ \\
\hline & Colorado & 7 & 244 & 451,000 & $15,587,000$ \\
\hline & Florida & 28 & 1,026 & 562,000 & $62,485,000$ \\
\hline & Idaho & 4 & 156 & 203,000 & $8,265,000$ \\
\hline & Indiana & 11 & 410 & 322,000 & $22,718,000$ \\
\hline & Louisiana & 13 & 459 & 172,000 & $26,037,000$ \\
\hline & Mississippi & 8 & 283 & 212,000 & $14,334,000$ \\
\hline & Missouri & 11 & 381 & 422,000 & $21,483,000$ \\
\hline & Montana & 7 & 264 & 154,000 & $14,363,000$ \\
\hline & Nevada & 3 & 117 & 257,000 & $7,422,000$ \\
\hline & New Hampshire & 2 & 68 & 168,000 & $4,453,000$ \\
\hline & New Jersey & 10 & 352 & 451,000 & $25,567,000$ \\
\hline & New Mexico & 1 & 49 & 231,000 & $2,606,000$ \\
\hline & New York & 18 & 635 & 575,000 & $44,998,000$ \\
\hline & North Carolina & 32 & 1,153 & 688,000 & $64,370,000$ \\
\hline & Oklahoma & 14 & 508 & 254,000 & $28,541,000$ \\
\hline & Oregon & 4 & 127 & 294,000 & $7,270,000$ \\
\hline & Pennsylvania & 23 & 830 & 664,000 & $50,876,000$ \\
\hline & South Carolina & 11 & 401 & 276,000 & $21,231,000$ \\
\hline & Tennessee & 21 & 762 & 378,000 & $41,976,000$ \\
\hline & Texas & 30 & 1,094 & $1,037,000$ & $65,023,000$ \\
\hline & Utah & 5 & 186 & 148,000 & $9,814,000$ \\
\hline & Vermont & 1 & 29 & 150,000 & $1,733,000$ \\
\hline & Virginia & 8 & 283 & 452,000 & $18,087,000$ \\
\hline & Washington & 4 & 137 & 274,000 & $8,716,000$ \\
\hline & West Virginia & 1 & 39 & 156,000 & $1,996,000$ \\
\hline & Wisconsin & 17 & 606 & 425,000 & $35,468,000$ \\
\hline $\begin{array}{l}\text { Limits on } \\
\text { diversion and } \\
\text { plea agreements }\end{array}$ & Alabama & 9 & 310 & 296,000 & $16,787,000$ \\
\hline
\end{tabular}




\begin{tabular}{llcccc}
\hline Intervention & State & Lives Saved & $\begin{array}{c}\text { Injuries } \\
\text { Prevented }\end{array}$ & Cost (\$) & Benefit (\$) \\
\hline Universal & Connecticut & 15 & 3,976 & 999,000 & $122,924,000$ \\
motorcycle & Delaware & 2 & 612 & 374,000 & $16,698,000$ \\
helmet laws & New Mexico & 11 & 2,982 & 529,000 & $71,514,000$ \\
& North Dakota & 4 & 1,147 & 310,000 & $28,419,000$ \\
& South Dakota & 8 & 2,064 & 394,000 & $50,667,000$ \\
& Wyoming & 10 & 2,523 & 309,000 & $68,729,000$ \\
\hline Total & 660 & 46,575 & $28,453,000$ & $1,878,160,000$ \\
\hline
\end{tabular}

NOTE: We have rounded lives saved and injuries prevented to the nearest decimal place, and benefits and costs to the nearest 1,000. The totals are based on the underlying numbers, so some slight inconsistencies are due to this rounding.

Several interesting observations arise from this analysis. For one, using this method, we cannot spend the full \$57.9 million on these interventions; most states would have to leave some money unspent because, after implementing one or more interventions, the remaining funds are insufficient to implement another. The group of interventions in Table 4.1 costs about \$28.4 million in total out of the available \$57.9 million.

Only six interventions of 11 are on the list, generally those that are implemented fairly cheaply (as Table 4.1 shows, all but five cost less than $\$ 1$ million to implement). Because the selection is limited by available funding, only 29 states can implement their most cost-effective intervention.

Although this spending method spreads the benefit widely, four states would not be able to spend any of their new funding. One of these is the District of Columbia, which effectively has only one intervention to implement, and its cost exceeds the 10-percent increase. In Maryland, the only two interventions not implemented are limits on diversion and plea agreements and inperson license renewal for older drivers, both of which exceed \$11 million, the amount that Maryland has available under this approach. In Hawaii and Massachusetts, all of the interventions available exceed the modest funding of $\$ 385,000$ and $\$ 846,000$, respectively.

In Alaska, Arkansas, Kansas, and Nebraska, funding is available to implement one intervention, but the impact is only on injuries prevented (that is, less than one life is saved per year). ${ }^{8}$ Two states, Mississippi and Vermont, can afford three interventions, and Indiana can afford four.

In the second analysis, we start with the same amount of money, but, this time, we have targeted the funds to the interventions with the highest cost-effectiveness ratios, regardless of state. To do this, we rank the interventions across all states by their cost-effectiveness ratios, creating one master list of state-intervention combinations. We work down the list, funding

\footnotetext{
${ }^{8}$ For both injuries and fatalities, MV PICCS rounds up to 1 for values of 0.5 and higher and rounds down to 0 for values 0.49 and lower. For consistency with the tool, we use the same approach in these analyses.
} 
interventions until all funds are allocated. Under this approach, we see a major difference in the number of lives saved-1,320, double the number in the first analysis - because the interventions are more effective (Table 4.2).

Table 4.2. Interventions That Could Be Funded with a 10-Percent Increase in Funding at the National Level

\begin{tabular}{|c|c|c|c|c|c|}
\hline Intervention & State & $\begin{array}{l}\text { Lives } \\
\text { Saved }\end{array}$ & $\begin{array}{c}\text { Injuries } \\
\text { Prevented }\end{array}$ & Cost (\$) & Benefit (\$) \\
\hline \multirow[t]{10}{*}{ Alcohol interlocks } & Idaho & 4 & 139 & 114,000 & $7,347,000$ \\
\hline & Indiana & 10 & 365 & 119,000 & $20,194,000$ \\
\hline & lowa & 10 & 347 & 118,000 & $19,755,000$ \\
\hline & Kentucky & 23 & 825 & 115,000 & $43,618,000$ \\
\hline & Maine & 4 & 148 & 119,000 & $8,265,000$ \\
\hline & Mississippi & 7 & 252 & 108,000 & $12,741,000$ \\
\hline & Nevada & 3 & 104 & 128,000 & $6,598,000$ \\
\hline & North Dakota & 4 & 139 & 115,000 & $7,892,000$ \\
\hline & Ohio & 23 & 842 & 123,000 & $47,953,000$ \\
\hline & South Dakota & 4 & 130 & 104,000 & $7,272,000$ \\
\hline \multirow{12}{*}{$\begin{array}{l}\text { In-person license } \\
\text { renewal for older } \\
\text { drivers }\end{array}$} & California & 35 & 3,180 & $1,815,000$ & $122,650,000$ \\
\hline & Georgia & 17 & 1,586 & 520,000 & $53,969,000$ \\
\hline & Indiana & 11 & 1,022 & 148,000 & $34,458,000$ \\
\hline & New Hampshire & 2 & 172 & 97,000 & $6,705,000$ \\
\hline & North Carolina & 16 & 1,455 & 620,000 & $49,721,000$ \\
\hline & South Dakota & 2 & 180 & 67,000 & $6,120,000$ \\
\hline & Tennessee & 12 & 1,095 & 449,000 & $36,836,000$ \\
\hline & Utah & 2 & 221 & 127,000 & $7,188,000$ \\
\hline & Vermont & 1 & 123 & 99,000 & $4,386,000$ \\
\hline & Washington & 6 & 523 & 422,000 & $20,024,000$ \\
\hline & West Virginia & 4 & 376 & 149,000 & $11,917,000$ \\
\hline & Wyoming & 2 & 164 & 69,000 & $6,372,000$ \\
\hline \multirow{9}{*}{$\begin{array}{l}\text { License plate } \\
\text { impoundment }\end{array}$} & Alabama & 21 & 762 & 118,000 & $41,205,000$ \\
\hline & California & 43 & 1,553 & $1,432,000$ & $100,424,000$ \\
\hline & Connecticut & 5 & 186 & 259,000 & $14,537,000$ \\
\hline & Florida & 28 & 1,026 & 562,000 & $62,485,000$ \\
\hline & Indiana & 11 & 410 & 322,000 & $22,718,000$ \\
\hline & Louisiana & 13 & 459 & 172,000 & $26,037,000$ \\
\hline & Mississippi & 8 & 283 & 212,000 & $14,334,000$ \\
\hline & Missouri & 11 & 381 & 422,000 & $21,483,000$ \\
\hline & Montana & 7 & 264 & 154,000 & $14,363,000$ \\
\hline
\end{tabular}




\begin{tabular}{|c|c|c|c|c|c|}
\hline Intervention & State & $\begin{array}{l}\text { Lives } \\
\text { Saved }\end{array}$ & $\begin{array}{l}\text { Injuries } \\
\text { Prevented }\end{array}$ & Cost (\$) & Benefit (\$) \\
\hline & New Jersey & 10 & 352 & 451,000 & $25,567,000$ \\
\hline & New York & 18 & 635 & 575,000 & $44,998,000$ \\
\hline & North Carolina & 32 & 1,153 & 688,000 & $64,370,000$ \\
\hline & Oklahoma & 14 & 508 & 254,000 & $28,541,000$ \\
\hline & Pennsylvania & 23 & 830 & 664,000 & $50,876,000$ \\
\hline & South Carolina & 11 & 401 & 276,000 & $21,231,000$ \\
\hline & South Dakota & 4 & 147 & 150,000 & $8,182,000$ \\
\hline & Tennessee & 21 & 762 & 378,000 & $41,976,000$ \\
\hline & Texas & 30 & 1,094 & $1,037,000$ & $65,023,000$ \\
\hline & Utah & 5 & 186 & 148,000 & $9,814,000$ \\
\hline & Wisconsin & 17 & 606 & 425,000 & $35,468,000$ \\
\hline & Wyoming & 6 & 215 & 171,000 & $14,174,000$ \\
\hline $\begin{array}{l}\text { Limits on } \\
\text { diversion and } \\
\text { plea agreements }\end{array}$ & Alabama & 9 & 310 & 296,000 & $16,787,000$ \\
\hline \multirow{24}{*}{$\begin{array}{l}\text { Universal } \\
\text { motorcycle } \\
\text { helmet laws }\end{array}$} & Alaska & 3 & 688 & 383,000 & $19,056,000$ \\
\hline & Arizona & 27 & 7,034 & $1,538,000$ & $172,088,000$ \\
\hline & Arkansas & 24 & 6,422 & 690,000 & $149,805,000$ \\
\hline & Colorado & 24 & 6,269 & $1,362,000$ & $168,276,000$ \\
\hline & Connecticut & 15 & 3,976 & 999,000 & $122,924,000$ \\
\hline & Delaware & 2 & 612 & 374,000 & $16,698,000$ \\
\hline & Florida & 114 & 30,275 & $5,515,000$ & $787,146,000$ \\
\hline & Hawaii & 8 & 1,988 & 485,000 & $52,738,000$ \\
\hline & Idaho & 8 & 2,141 & 527,000 & $50,819,000$ \\
\hline & Illinois & 38 & 10,015 & $3,299,000$ & $266,122,000$ \\
\hline & Indiana & 32 & 8,486 & $1,840,000$ & $206,284,000$ \\
\hline & lowa & 17 & 4,587 & $1,174,000$ & $113,340,000$ \\
\hline & Kansas & 12 & 3,058 & 768,000 & $77,045,000$ \\
\hline & Kentucky & 28 & 7,339 & 860,000 & $174,616,000$ \\
\hline & Maine & 5 & 1,453 & 473,000 & $36,063,000$ \\
\hline & Minnesota & 14 & 3,670 & $1,766,000$ & $98,164,000$ \\
\hline & Montana & 8 & 1,988 & 629,000 & $48,280,000$ \\
\hline & New Hampshire & 8 & 2,141 & 613,000 & $59,344,000$ \\
\hline & New Mexico & 11 & 2,982 & 529,000 & $71,514,000$ \\
\hline & North Dakota & 4 & 1,147 & 310,000 & $28,419,000$ \\
\hline & Ohio & 49 & 12,997 & $3,088,000$ & $323,271,000$ \\
\hline & Oklahoma & 23 & 5,963 & 878,000 & $147,166,000$ \\
\hline & Pennsylvania & 64 & 17,049 & $3,398,000$ & $444,594,000$ \\
\hline & Rhode Island & 4 & 1,147 & 403,000 & $30,734,000$ \\
\hline
\end{tabular}




\begin{tabular}{llcccc}
\hline \multirow{2}{*}{ Intervention } & \multicolumn{1}{c}{ State } & $\begin{array}{c}\text { Lives } \\
\text { Saved }\end{array}$ & $\begin{array}{c}\text { Injuries } \\
\text { Prevented }\end{array}$ & Cost (\$) & Benefit (\$) \\
\hline & South Carolina & 29 & 7,722 & $1,027,000$ & $185,303,000$ \\
& South Dakota & 8 & 2,064 & 394,000 & $50,667,000$ \\
& Texas & 120 & 31,728 & $4,652,000$ & $810,072,000$ \\
& Utah & 6 & 1,529 & 634,000 & $36,294,000$ \\
& Wisconsin & 30 & 8,028 & $2,085,000$ & $204,918,000$ \\
& Wyoming & 10 & 2,523 & 309,000 & $68,729,000$ \\
\hline Primary seat & West Virginia & 18 & 1,943 & $1,272,000$ & $58,102,000$ \\
belt-use laws & Wyoming & 8 & 879 & 611,000 & $32,075,000$ \\
\hline Total & & 1,320 & 225,752 & $57,796,000$ & $6,397,240,000$ \\
\hline
\end{tabular}

NOTE: We have rounded lives saved and injuries prevented to the nearest decimal place, and benefits and costs to the nearest 1,000. The totals are based on the underlying numbers, so some slight inconsistencies are due to this rounding.

Interestingly, the actual number of interventions funded under this approach, 76, is slightly lower than under the approach in which each state received a 10-percent increase in funding, which funded 78. But the balance of the type of interventions that are funded changes quite dramatically. Instead of bicycle helmet laws, which are inexpensive but save relatively few lives, we can now implement universal motorcycle helmet laws, which are more expensive to implement but also much more cost-effective, in all 30 states that do not currently have them. This intervention alone saves 745 lives.

The national approach also allocates much more of the hypothetical increase in funding, \$57.9 million. Even if we used this approach and spent the same amount, \$28.4 million, as under the prior scenario, more lives would be saved-717, as opposed to 660 .

The national approach, however, concentrates spending in fewer states: 44 as opposed to 47 . Of the seven states where no new intervention would be implemented, three are the same as in the 10-percent increase for each state: the District of Columbia, Maryland, and Massachusetts. Maryland and Oregon have already implemented most of the 11 interventions under consideration (nine in Maryland and eight in Oregon). The three other states-Michigan, Nebraska, and Virginia — do not have any potential interventions that exceed a 44-to-1 costeffectiveness ratio, which ended up being the minimum ratio that this approach selected (that is, the last of the 76 interventions to be selected had a 44-to- 1 cost-effectiveness ratio, so no interventions with a lower ratio were selected).

As in Chapter Three, selecting interventions to fund based on a broader perspective without regard to location is more cost-effective than doing something for every state. Because the states have such varying levels of existing interventions, some states would see only very modest gains in traffic safety, even if substantial funding were available, while others could save dozens of lives for relatively low costs if they spend those funds on cost-effective interventions. 



\section{Chapter Five. Given This Set of Interventions, What Is the Most Cost-Effective Way to Reduce Drunk Driving?}

Drunk driving remains a major cause of fatal crashes. Overall, about 31 percent of motor vehicle-related fatalities in 2010 involved drivers who were alcohol-impaired (NHTSA, undated [a]). ${ }^{9}$ Although the absolute number of drunk driving-related deaths has declined with the overall decline in vehicle crash-related deaths, this percentage has remained roughly constant. The legal standard for a DWI charge is a BAC of $0.08 .{ }^{10}$

The extent of the drunk-driving problem varies from state to state, although there are differences depending on how the problem is measured. Three metrics are commonly used:

- proportion of a state's vehicle crash fatalities attributable to drunk driving: The proportion of fatalities attributable to alcohol-impaired driving ranges from 19 percent in Iowa to 48 percent in North Dakota. The average for the United States is 31 percent, but 14 states have rates of 37 percent or more.

- death rate per 100,000 people attributable to drunk driving: Across states, this ranges from 1.5 in New York and Massachusetts to 10.8 in Wyoming. The U.S. average is 3.3, but 13 states have rates of five or higher.

- total number of deaths attributable to drunk driving: Thirteen states have 250 or more fatalities caused by drunk driving. Obviously, states with higher numbers of fatalities because of larger populations will likely have higher numbers of drunk driving-related fatalities as well. Almost one-quarter of the country's total deaths from drunk driving were in three states: Texas, California, and Florida. These three also have similar shares of total fatalities and total population.

This analysis considers five interventions; ${ }^{11}$ most states have implemented two or three of these. Four of the five interventions deal with recidivist drunk drivers, who constitute a small number of drivers but account for a higher share of crashes than other drivers (Century Council, 2008). Figure 5.1 graphs the number of interventions in a state by the number of DWI deaths per 100,000 people, and Table 5.1 shows the average by group. There is a negative correlation between the number of interventions and the DWI death rate. Although this relationship is not

\footnotetext{
${ }^{9}$ We use data from the 2010 FARS for all numbers to match the figures incorporated into the MV PICCS tool. They were the most recent available when we conducted this portion of the analysis. In FARS, alcohol-impaired includes both drivers whose BAC tested at 0.08 or above and drivers whose blood was not tested and therefore have imputed values only.

${ }^{10}$ All states have anti-drunk driving laws that consider this BAC level the legal limit for a formal charge. State terminology varies; a DWI charge against a drunk driver is the same as a charge of driving under the influence. For the sake of consistency, this report uses DWI.

${ }^{11}$ The tool contains information on six anti-drunk driving interventions, but, in this analysis, we do not consider one of these, saturation patrols, because it was difficult to ascertain where this intervention is already in place.
} 
necessarily causal, it does indicate that states with more interventions tend to have lower rates of fatalities from drunk driving.

Figure 5.1. Scatterplot of Number of Interventions, by Proportion of Fatalities Related to AlcoholImpaired Driving

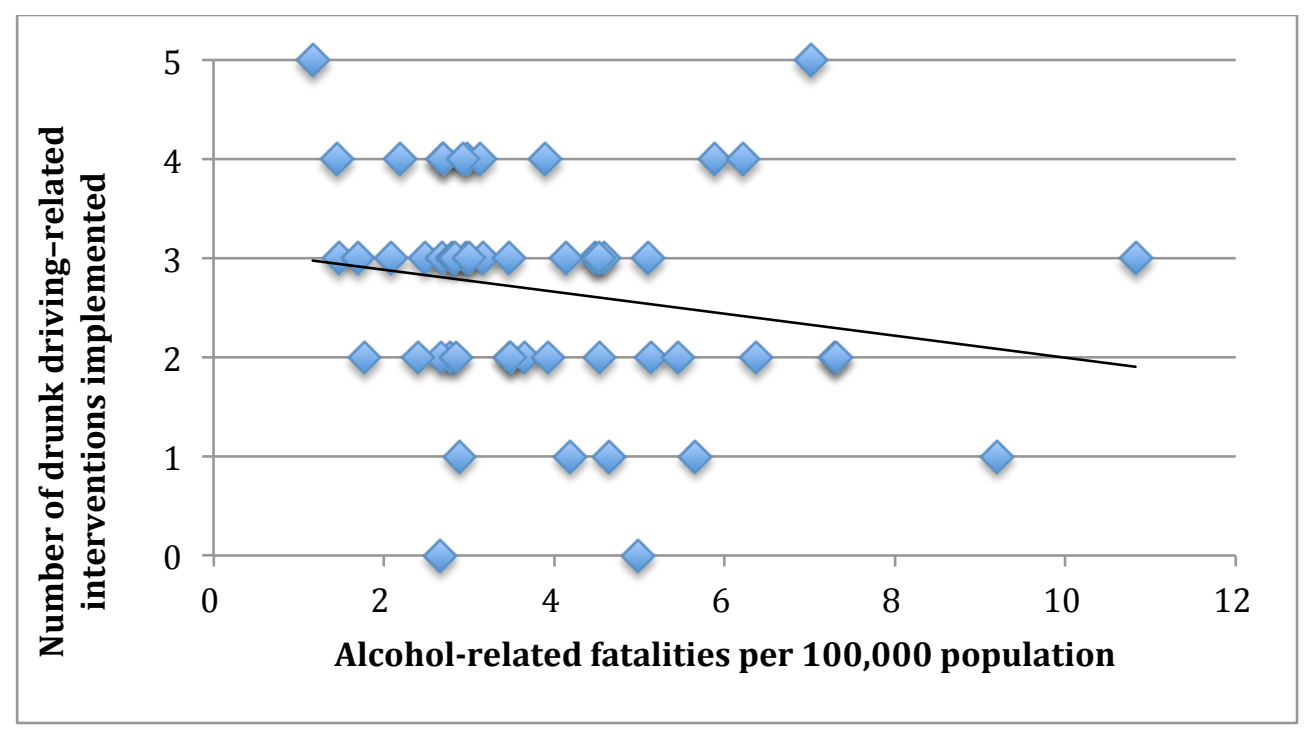

SOURCE: Analysis of FARS data from NHTSA, undated (a).

Table 5.1. Average Number of Drunk Driving-Related Fatalities, by Number of Interventions

\begin{tabular}{lcc}
\hline $\begin{array}{l}\text { Number of } \\
\text { Interventions }\end{array}$ & $\begin{array}{c}\text { Number of } \\
\text { States }\end{array}$ & $\begin{array}{c}\text { Average Number of Drunk Driving-Related Fatalities per } \\
\text { 100,000 Population }\end{array}$ \\
\hline 0 & 2 & 3.8 \\
1 & 5 & 5.3 \\
2 & 15 & 4.2 \\
3 & 17 & 3.7 \\
4 & 10 & 3.4 \\
5 & 2 & 4.1 \\
Total & 51 & 3.3 \\
\hline
\end{tabular}

SOURCE: Analysis of FARS data from NHTSA, undated (a).

To find the most cost-effective interventions, we need to look at the cost-effectiveness of each intervention in each state, then rank them. We use the same approach as we did in Chapter Three, but focusing solely on interventions to address DWI. Specifically, we first exclude those DWI interventions in states where they are already in place. There are 255 possible interventionstate combinations (51 states times five interventions), and excluding those that are already in 
use leaves 119. Figure 5.2 shows these 119 combinations in declining order of their costeffectiveness ratios.

Figure 5.2. Cost-Effectiveness Ratios for 119 Anti-Drunk Driving Interventions

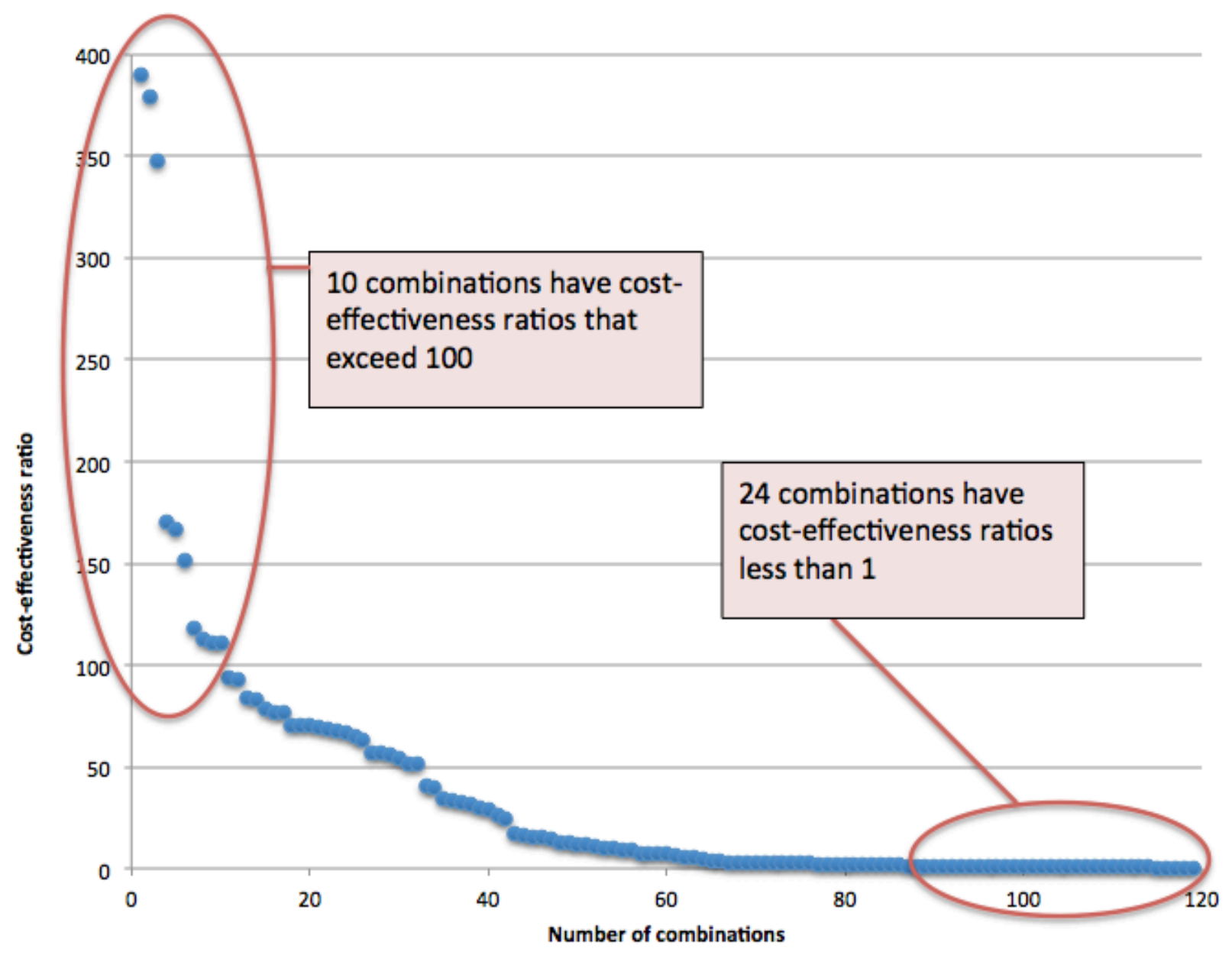

With our assumptions and the data underlying the tool, we can calculate the costs and effectiveness of implementing all 119 combinations of the five DWI interventions in states that do not currently have them. If all five DWI interventions were implemented in states that do not currently have them, the United States could save 1,182 lives and prevent 52,693 injuries annually. This would cost about $\$ 764$ million, and the monetized benefit is $\$ 2.7$ billion. The cost-effectiveness ratio of this approach is 3.53, meaning that, on the whole, these interventions provide $\$ 3.53$ of benefit for every $\$ 1$ spent.

Although this is a positive cost-effectiveness ratio, other ways to reduce drunk driving might be even more cost-effective. To determine this, we need to look for specific interventions with higher cost-effectiveness ratios. 
Each dot in Figure 5.2 represents one combination, and they are arranged in declining order by cost-effectiveness ratio. In general, one does not want to implement policies with costeffectiveness ratios less than 1 because those costs outweigh the benefits. To maximize the safety gains from the dollars spent on traffic safety, we want to start with the combinations with the highest cost-effectiveness ratios.

Figure 5.2 shows that the cost-effectiveness ratio declines rapidly because only a handful of combinations have very high cost-effectiveness ratios. In ten cases, the cost-effectiveness ratios exceed 100. In 24 cases, the ratios are less than 1. Although there is nothing particularly significant about a cost-effectiveness ratio of 100, implementing those ten cases will do a better job of maximizing the impact of traffic safety spending.

Of the ten highest combinations with the highest cost-effectiveness ratios, five are license plate impoundment and five are alcohol interlocks. These rank high in cost-effectiveness terms because they are both sanctions that take place after arrest and thus do not impose additional costs to the police or court system. Also, offenders are required to purchase the interlocks, which means that the cost to the state is low.

The total cost of implementing these ten combinations is $\$ 2.1$ million, and they would save 170 lives. That works out to a collective cost-effectiveness ratio of 167 . Table 5.2 shows the ten combinations.

Table 5.2. Ten Instances with the Highest Cost-Effectiveness Ratios

\begin{tabular}{|c|c|c|c|c|c|c|}
\hline State & Intervention & $\begin{array}{l}\text { Lives } \\
\text { Saved }\end{array}$ & $\begin{array}{c}\text { Injuries } \\
\text { Prevented }\end{array}$ & Cost (\$) & Benefit (\$) & $\begin{array}{c}\text { Cost- } \\
\text { Effectiveness } \\
\text { Ratio }\end{array}$ \\
\hline Ohio & Alcohol interlocks & 23 & 842 & 123,000 & $47,953,000$ & 390 \\
\hline Kentucky & Alcohol interlocks & 23 & 825 & 115,000 & $43,618,000$ & 379 \\
\hline Alabama & License plate impoundment & 21 & 762 & 118,000 & $41,205,000$ & 348 \\
\hline Indiana & Alcohol interlocks & 10 & 365 & 119,000 & $20,194,000$ & 170 \\
\hline lowa & Alcohol interlocks & 10 & 347 & 118,000 & $19,755,000$ & 167 \\
\hline Louisiana & License plate impoundment & 13 & 459 & 172,000 & $26,037,000$ & 152 \\
\hline Mississippi & Alcohol interlocks & 7 & 252 & 108,000 & $12,741,000$ & 118 \\
\hline Oklahoma & License plate impoundment & 14 & 508 & 254,000 & $28,541,000$ & 112 \\
\hline Tennessee & License plate impoundment & 21 & 762 & 378,000 & $41,976,000$ & 111 \\
\hline Florida & License plate impoundment & 28 & 1,026 & 562,000 & $62,485,000$ & 111 \\
\hline Total & & 170 & 6,148 & $2,067,000$ & $344,506,000$ & 167 \\
\hline
\end{tabular}

NOTE: We have rounded the numbers of lives saved and injuries prevented to the nearest decimal place. We have rounded the amounts of benefits and costs to the nearest 1,000. The totals and cost-effectiveness ratios are based on the underlying numbers, so some slight inconsistencies are due to this rounding.

Comparing the costs and benefits of implementing these ten instances with the highest benefit-cost ratio with all 119 combinations suggests that we would save 14 percent of all the 
lives that could be saved through these particular DWI interventions $(170 \div 1,182)$ for less than 0.5 percent of the cost $(\$ 2.1$ million $\div \$ 764$ million).

This analysis shows that states vary in the costs and effectiveness of each intervention, and interventions that might be highly cost-effective in one state might be less so in another. If budgets are limited, the most cost-effective way to reduce DWI deaths and injuries is to implement the most cost-effective interventions. 



\section{Chapter Six. Conclusion}

In this report, we used state-level cost-effectiveness data for a set of motor vehicle-related injury-prevention interventions to consider three policy questions from a national perspective.

\section{What Are the Effects of Implementing the Most Cost-Effective Interventions?}

For the nation as a whole, under our assumptions, the three most cost-effective interventions are alcohol interlocks, universal motorcycle helmet laws, and license plate impoundment. If these three interventions were implemented in all states where they are not currently in place, 1,219 fatalities would be prevented, and implementation costs would be approximately $\$ 55$ million. Universal motorcycle helmet laws alone would prevent 745 fatalities and cost $\$ 41$ million to implement. If we take a different, state-specific approach that selects the most cost-effective intervention in each state for implementation, the interventions together would prevent 928 fatalities and cost about $\$ 60$ million to implement. The national approach is more cost-effective, in that more fatalities are prevented at a lower cost, but does not spread the reduction in fatalities across all states. Under the national approach, nothing changes in states that already have the most cost-effective interventions in place. This highlights a trade-off between cost-effectiveness and equity among states that policymakers would face in choosing among these different approaches to reducing motor vehicle-related injuries and fatalities.

\section{What Is the Most Cost-Effective Way to Allocate an Increase in Funding for Interventions?}

If additional funding were available at the national level to implement motor vehicle-related injury-prevention interventions, the most cost-effective way to allocate the funds would be to target the funding to the most cost-effective interventions regardless of state. For example, we estimated the effects of a 10-percent increase in funding (approximately \$57.9 million) and found that, when targeted to the most cost-effective interventions, that funding would allow a total of 76 interventions to be implemented in 44 states. The interventions together would prevent 1,320 fatalities and use the majority of the available funding ( $\$ 57.8$ million). Although this approach is more cost-effective than giving each state a 10-percent increase in funding, which prevents 660 fatalities and is able to use only about half the available funds, it does not spread the benefit of reduced fatalities across as many states. Policymakers again face an important trade-off between cost-effectiveness and equity among states when considering different ways to allocate an increase in funding. 


\section{Given This Set of Interventions, What Is the Most Cost-Effective Way to Reduce Drunk Driving?}

States vary in the costs and effectiveness of each of the DWI interventions. As a result, interventions that might be highly cost-effective in one state might be less so in another. When budgets are limited, the most cost-effective way to reduce DWI deaths and injuries is to target implementation of the most cost-effective interventions regardless of state. Some stateintervention combinations have very high cost-effectiveness ratios under our assumptions. In fact, ten intervention-state combinations have cost-effectiveness ratios greater than 100, meaning that the monetized benefits in terms of reduced injuries and fatalities is at least $\$ 100$ for each $\$ 1$ spent on implementation. We find that implementing these ten state-intervention combinations would cost $\$ 2.1$ million and would prevent 170 fatalities. That works out to a collective costeffectiveness ratio of 167 . When less cost-effective interventions are added to the mix, more deaths are prevented, but the cost of doing so gets very high.

\section{Final Thoughts}

Overall, we find that strategies that focus on identifying and implementing the most costeffective interventions, regardless of location, make the most effective use of limited traffic safety dollars. These strategies, however, might raise some concerns about equity among states because they generally do not spread the benefits of reduced injuries and deaths across all states. Strategies that seek to make changes in each state might be seen as more equitable but lead to a less effective use of the limited resources. This is particularly true in states that have already implemented the most cost-effective interventions and thus must implement interventions with low cost-effectiveness ratios under these scenarios.

As noted earlier, these estimates rely on a variety of estimates and assumptions, which we detail elsewhere (Ringel et al., forthcoming). These include cost (such as estimating the number of staff-hours required and assuming that costs across states are similar), benefits (such as basing injury reduction on fatality reduction), data sources (such as using data that, in some cases, are inconsistent across states), and implementation (such as assuming a certain intensity of implementation, such as the number of sobriety checkpoints needed).

The results presented here should be considered approximate. They are meant to give policymakers a sense of the relative costs and effects of the different interventions under consideration and to constitute one category of information in the larger policy debate.

Despite the necessary reliance on assumptions to build the model, we believe that the analyses can be of great use to state policymakers. Although information about which interventions are effective has been generally available, this is the first effort, to our knowledge, to estimate the implementation costs across a broad array of interventions and to translate these costs to the state level according to a specific state's demographics and traffic crash profile. 
Policymakers at both the national and state levels need information on the potential costs and effects of interventions to make informed resource-allocation decisions to help reduce the enormous human and financial toll of traffic crashes. 



\section{Appendix. Reference Tables}

This appendix contains several key tables that summarize some of the data underlying the model. 
Table A.1. Cost Components and Subcomponents, by Intervention and Type of Cost

\begin{tabular}{|c|c|c|c|c|c|c|c|c|c|c|c|c|c|c|c|}
\hline Cost Component and Unit & Type of Cost & 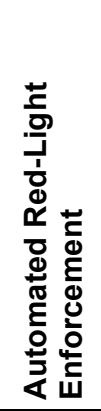 & 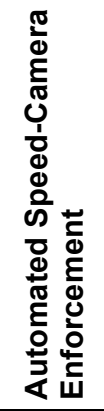 & 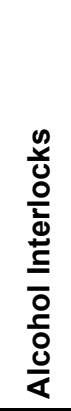 & 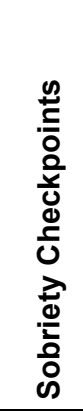 & 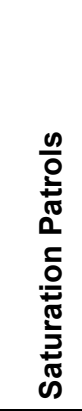 & 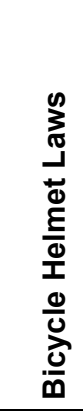 & 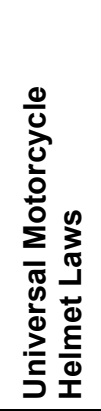 & 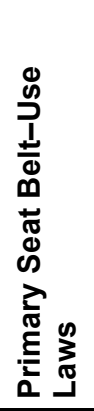 & 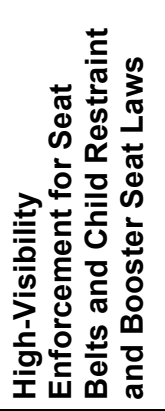 & 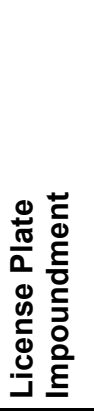 & 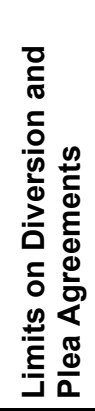 & 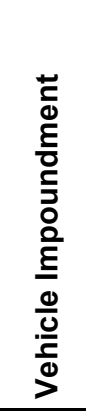 & 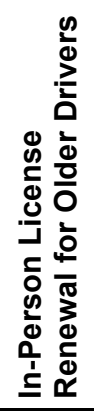 & 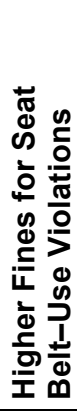 \\
\hline \multicolumn{16}{|l|}{ Publicity cost } \\
\hline Print advertising, $\$ / 1,000$ drivers & Cost to state & 18 & 18 & - & 18 & 18 & 18 & 18 & - & - & - & - & - & - & - \\
\hline $\begin{array}{l}\text { Outdoor advertising, } \\
\$ / 1,000 \text { drivers }\end{array}$ & Cost to state & 10 & 10 & - & 10 & 10 & 10 & 10 & - & - & - & - & - & - & - \\
\hline Radio advertising, $\$ / 1,000$ drivers & Cost to state & 42 & 42 & - & 42 & 42 & 42 & 42 & - & - & - & - & - & - & - \\
\hline $\begin{array}{l}\text { Television advertising, } \\
\$ / 1,000 \text { drivers }\end{array}$ & Cost to state & 119 & 119 & - & 119 & 119 & 119 & 119 & - & - & - & - & - & - & - \\
\hline CIOT media campaign & Cost to state & - & - & - & - & - & - & - & - & a & - & - & - & - & - \\
\hline \multicolumn{16}{|l|}{ Police or highway patrol time } \\
\hline $\begin{array}{l}\text { Police costs, full-scale sobriety } \\
\text { checkpoint, hours/wave }\end{array}$ & Cost to state & - & - & - & 40 & - & - & - & - & - & - & - & - & - & - \\
\hline $\begin{array}{l}\text { Police costs, full-scale saturation } \\
\text { patrol, hours/patrol }\end{array}$ & Cost to state & - & - & - & - & 40 & - & - & - & - & - & & 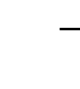 & - & \\
\hline $\begin{array}{l}\text { Police costs, automated speed- } \\
\text { camera enforcement, \$/citation }\end{array}$ & Cost to state & 7 & 7 & - & - & - & - & - & - & - & - & - & - & - & - \\
\hline $\begin{array}{l}\text { Police costs, universal } \\
\text { motorcycle helmet laws, \$/citation }\end{array}$ & Cost to state & - & - & - & - & - & - & 928 & - & - & - & - & - & - & - \\
\hline $\begin{array}{l}\text { Police costs, high-visibility } \\
\text { enforcement for seat belts and } \\
\text { child restraint and booster seat } \\
\text { laws, hours/citation }\end{array}$ & Cost to state & - & - & - & - & - & - & - & 1.7 & 1.7 & - & - & - & - & - \\
\hline
\end{tabular}




\begin{tabular}{|c|c|c|c|c|c|c|c|c|c|c|c|c|c|c|c|}
\hline Cost Component and Unit & Type of Cost & 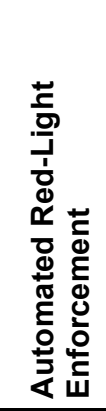 & 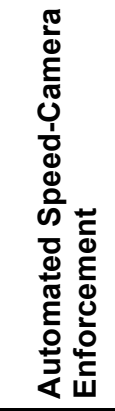 & 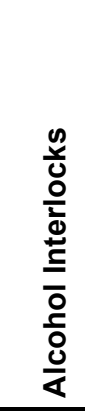 & 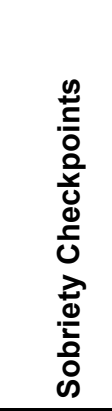 & 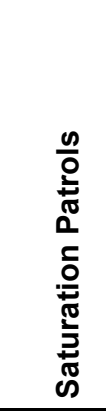 & 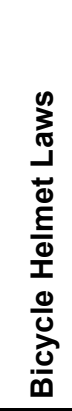 & 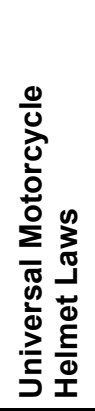 & 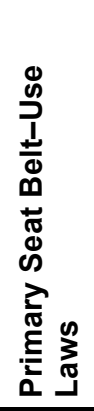 & 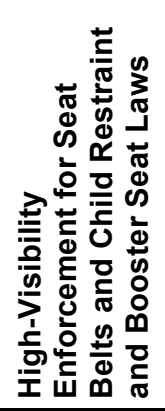 & 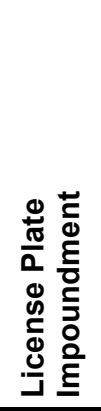 & 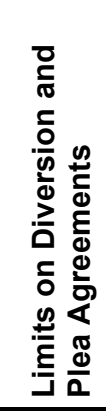 & 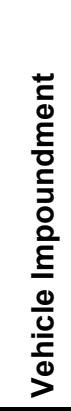 & 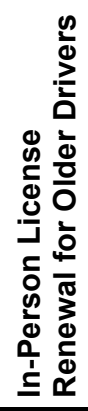 & 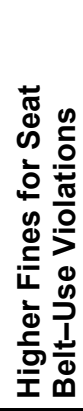 \\
\hline \multicolumn{16}{|l|}{ Court system } \\
\hline Prosecution costs, \$/offender & Cost to state & - & - & - & 2,279 & - & - & - & - & - & - & - & - & - & - \\
\hline Lawyer for DWI, \$/offender ${ }^{\mathrm{b}}$ & Offender cost & - & - & - & 2,571 & 2,571 & - & - & - & - & - & 2,571 & - & - & - \\
\hline \multicolumn{16}{|l|}{ DMV staff } \\
\hline $\begin{array}{l}\text { License reinstatement, } \\
\text { hours/occurrence }\end{array}$ & Cost to state & - & - & - & 0.5 & 0.5 & - & - & - & - & - & 0.5 & - & - & - \\
\hline $\begin{array}{l}\text { License plate reinstatement, } \\
\text { hours/occurrence }\end{array}$ & Cost to state & - & - & - & - & - & - & - & - & - & 0.5 & - & - & - & - \\
\hline $\begin{array}{l}\text { In-person license renewal for } \\
\text { older drivers, \$/additional driver }\end{array}$ & Cost to state & - & - & - & - & - & - & - & - & - & - & - & - & 12 & - \\
\hline \multicolumn{16}{|c|}{ Equipment acquisition, replacement, and maintenance } \\
\hline $\begin{array}{l}\text { Camera lease costs, } \\
\$ / \text { camera/month }\end{array}$ & Cost to state & 5,868 & 5,868 & - & - & - & - & - & - & - & - & - & - & - & - \\
\hline Alcohol interlocks, \$/interlock & Offender cost & - & - & 402 & - & - & - & - & - & - & - & - & - & - & - \\
\hline $\begin{array}{l}\text { Police equipment, saturation } \\
\text { patrols, } \$ / \text { patrol based on road } \\
\text { network }\end{array}$ & Cost to state & - & - & - & - & 100 & - & - & - & - & - & - & - & - & - \\
\hline $\begin{array}{l}\text { Police equipment, sobriety } \\
\text { checkpoints, \$/checkpoint }\end{array}$ & Cost to state & - & - & - & 5,448 & - & - & - & - & - & - & - & - & - & - \\
\hline Passive alcohol sensors, \$/patrol & Cost to state & - & - & - & - & 1,182 & - & - & - & - & - & - & - & - & - \\
\hline $\begin{array}{l}\text { Children's bicycle helmet laws, } \\
\$ / \text { helmet }\end{array}$ & Compliance cost & - & - & - & - & - & 20 & - & - & - & - & - & - & - & - \\
\hline $\begin{array}{l}\text { Universal motorcycle helmet } \\
\text { laws, } \$ / \text { helmet }\end{array}$ & Compliance cost & - & - & - & - & - & - & 100 & - & - & - & - & - & - & - \\
\hline
\end{tabular}




\begin{tabular}{|c|c|c|c|c|c|c|c|c|c|c|c|c|c|c|c|}
\hline Cost Component and Unit & Type of Cost & 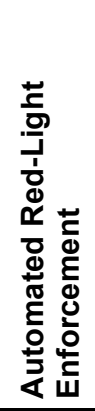 & 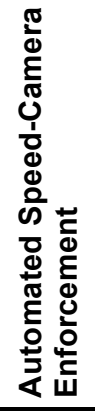 & 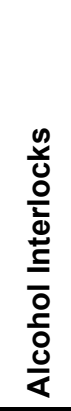 & 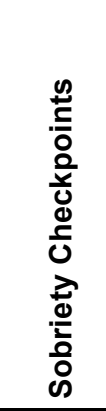 & 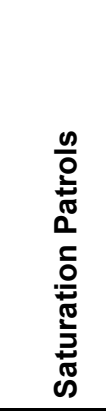 & 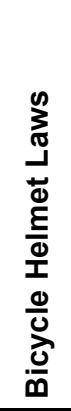 & 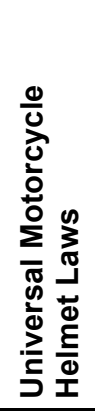 & 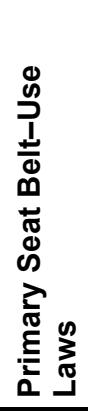 & 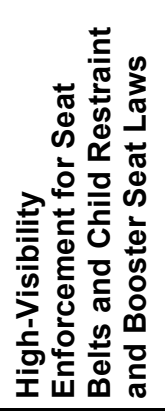 & 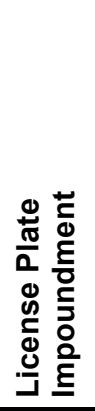 & 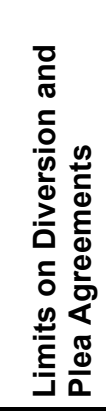 & 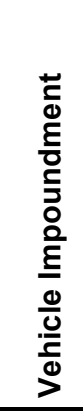 & 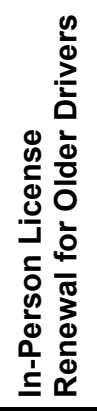 & 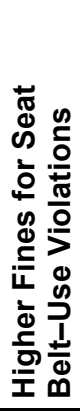 \\
\hline Infant car seat, \$/seat & Compliance cost & - & - & - & - & - & - & - & - & 125 & - & - & - & - & - \\
\hline Children's booster seat, \$/seat & Compliance cost & - & - & - & - & - & - & - & - & 60 & - & - & - & - & - \\
\hline \multicolumn{16}{|l|}{ Fines, fees, and charges } \\
\hline $\begin{array}{l}\text { Universal motorcycle helmet law } \\
\text { fine, \$/citation }\end{array}$ & State revenue & - & - & - & - & - & - & 147 & - & - & - & - & - & - & - \\
\hline Seat belt fine, $\$ /$ citation & State revenue & - & - & - & - & - & - & - & 34 & 34 & - & - & - & - & - \\
\hline $\begin{array}{l}\text { Child or booster seat fine, } \\
\$ / \text { citation }\end{array}$ & State revenue & - & - & - & - & - & - & - & - & 65 & - & - & - & - & - \\
\hline $\begin{array}{l}\text { Driver's license reinstatement } \\
\text { fee, DWI, \$/offender }\end{array}$ & State revenue & - & - & - & 204 & 204 & - & - & - & - & - & 204 & - & - & - \\
\hline $\begin{array}{l}\text { License plate fee, DWI, } \\
\text { \$loffender }\end{array}$ & State revenue & - & - & - & - & - & - & - & - & - & 204 & - & - & - & - \\
\hline $\begin{array}{l}\text { Moving violations for automated } \\
\text { speed-camera enforcement, } \\
\text { \$/citation }\end{array}$ & State revenue & - & 145 & - & - & - & - & - & - & - & - & - & - & - & - \\
\hline $\begin{array}{l}\text { Moving violations for automated } \\
\text { red-light enforcement, \$/citation }\end{array}$ & State revenue & 120 & - & - & - & - & - & - & - & - & - & - & - & - & - \\
\hline $\begin{array}{l}\text { Court fines related to DWI, } \\
\$ \text { /offender }\end{array}$ & State revenue & - & - & - & 2,000 & 2,000 & - & - & - & - & - & 2,000 & - & - & - \\
\hline $\begin{array}{l}\text { Vehicle impoundment fees, } \\
\text { \$/impounded vehicle }\end{array}$ & State revenue & - & - & - & - & - & - & - & - & - & - & - & 520 & - & - \\
\hline $\begin{array}{l}\text { Higher fines for seat belt-use } \\
\text { violations, \$/citation }\end{array}$ & State revenue & - & - & - & - & - & - & - & - & - & - & - & - & - & 75 \\
\hline \multicolumn{16}{|l|}{ Probation cost } \\
\hline Probation, \$/probationer & Cost to state & - & - & - & 2,922 & 2,922 & - & - & - & - & - & 2,922 & - & - & - \\
\hline
\end{tabular}




\begin{tabular}{|c|c|c|c|c|c|c|c|c|c|c|c|c|c|c|c|}
\hline Cost Component and Unit & Type of Cost & 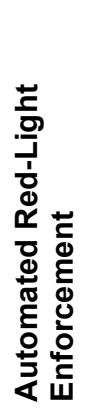 & 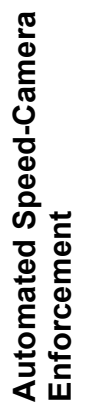 & 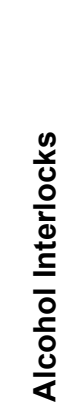 & 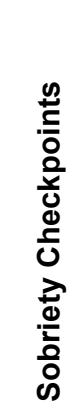 & 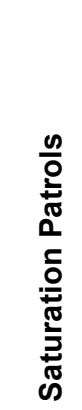 & 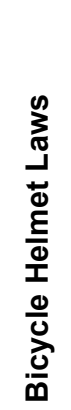 & 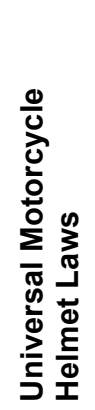 & 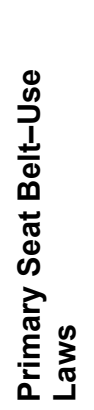 & 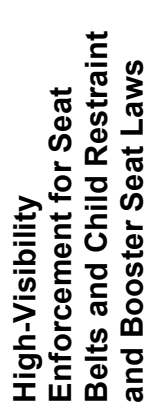 & 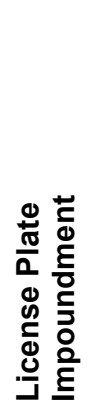 & 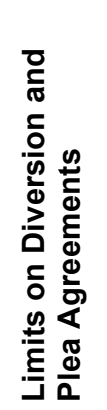 & 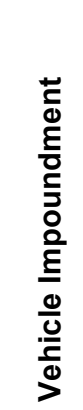 & 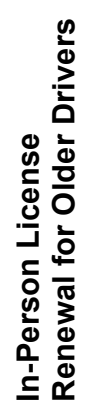 & 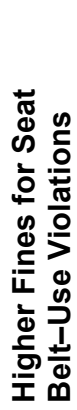 \\
\hline \multicolumn{16}{|l|}{ Education program } \\
\hline $\begin{array}{l}\text { Alcohol education program, } \\
\text { \$/attendee paid by attendee }\end{array}$ & State revenue & - & - & - & 294 & 294 & - & - & - & - & - & 294 & - & - & - \\
\hline $\begin{array}{l}\text { Alcohol education program, } \\
\text { \$/attendee paid by state }\end{array}$ & Cost to state & - & - & - & 254 & 254 & - & - & - & - & - & 254 & - & - & - \\
\hline \multicolumn{16}{|l|}{ Impoundment cost } \\
\hline $\begin{array}{l}\text { Tow staffing costs, \$/impounded } \\
\text { vehicle }\end{array}$ & Cost to state & - & - & - & - & - & - & - & - & - & - & - & 637 & - & - \\
\hline \multicolumn{16}{|l|}{ Program management } \\
\hline $\begin{array}{l}\text { Program management, full-time } \\
\text { equivalent/program }\end{array}$ & Cost to state & 2.5 & 2.5 & 2.5 & 2.5 & 2.5 & 1 & 2.5 & 2.5 & 2.5 & 2.5 & 2.5 & 2.5 & - & - \\
\hline Total subcomponents included in cost & & 8 & 8 & 1 & 16 & 16 & 5 & 7 & 3 & 5 & 3 & 10 & 3 & 1 & 1 \\
\hline
\end{tabular}

SOURCES: All figures are our estimates based on a variety of published sources, as well as interviews. Detailed explanations are available in Ringel et al., forthcoming.

NOTE: $-=$ not applicable. CIOT $=$ Click It or Ticket, a type of high-visibility enforcement campaign. All costs are annual and in 2012 dollars unless otherwise noted.

These include all four types of costs, as discussed in the "Implementation Cost Estimation" section of Chapter Two.

a Assumes $\$ 39$ million (in 2012 dollars) across all states, allocated based on population.

${ }^{b}$ In the base model, we do not include the cost to the offender. We provide it as information to the state on the potential burden on offenders. This assumes that all offenders will use lawyers. In reality, some offenders will not use lawyers, while others will spend significantly more on representation. So this is just to provide a roughorder-of-magnitude estimate of expenditures by offenders. 
Table A.2. Basis for Estimates of Injury and Death Reduction

\begin{tabular}{ll}
\hline Intervention & \multicolumn{1}{c}{ Estimated Effect } \\
\hline $\begin{array}{l}\text { Automated red-light } \\
\text { enforcement }\end{array}$ & $\begin{array}{l}17 \% \text { of deaths at } \\
\text { intersections with signals }\end{array}$ \\
$\begin{array}{l}\text { Automated speed- } \\
\text { camera enforcement }\end{array}$ & $\begin{array}{l}12 \% \text { reduction in speed- } \\
\text { related crashes }\end{array}$ \\
Alcohol interlocks & $\begin{array}{l}24 \% \text { reduction in crashes of } \\
\text { those with previous DWI } \\
\text { convictions }\end{array}$
\end{tabular}

Sobriety checkpoints

$8.1 \%$ reduction in alcoholrelated deaths; $20 \%$ reduction in injuries

\section{Source}

For Hu, McCartt, and Teoh, 2011, the authors conducted panel data analysis and found that automated red-light enforcement reduces fatal crashes by $17 \%$. We assume proportional responses on injuries.

For Cunningham, Hummer, and Moon, 2005, the authors studied North Carolina speed limit-enforcement cameras and found a $12 \%$ reduction in speed-related crashes. We assume a proportional response in injuries and deaths.

For DeYoung, Tashima, and Masten, 2005, the authors studied California's interlock program, comparing DWI offenders with interlock restrictions and those without. They found a $24 \%$ reduction in crashes. We assume a proportional response on both injuries and deaths.

For Fell, Tippetts, and Levy, 2008, the authors studied demonstration projects using FARS data. They studied 7 programs, and we take the average effect as our main estimate. The authors of Elder et al., 2002, conducted a systematic review of the effects of selective breath testing checkpoints and reported a median finding in the literature of a $20 \%$ reduction in fatal and nonfatal injury crashes.

\section{Saturation patrols}

Bicycle helmet laws

Universal motorcycle helmet laws

Primary seat belt-use laws

High-visibility enforcement for seat belts and child restraint and booster seat laws

License plate impoundment

Limits on diversion and plea agreements

Vehicle impoundment
$17.9 \%$ reduction in alcoholrelated deaths

$15 \%$ reduction in cyclist deaths

$28.9 \%$ reduction in motorcyclist deaths

$7 \%$ reduction in deaths involving passenger vehicles

$5.4 \%$ reduction in deaths involving passenger vehicles

$27 \%$ reduction in recidivism for those with previous DWI convictions

$11 \%$ reduction in recidivism for those with previous DWI convictions

$30.4 \%$ reduction in crashes for those with previous DWI convictions
Fell, Tippetts, and Levy, 2008, cites a $17.9 \%$ drop in fatal crashes in Michigan. We assume a proportional response on injuries.

For Grant and Rutner, 2004, the authors studied the effect on juvenile cyclist deaths. We assume a proportional effect on injuries.

Sass and Zimmerman, 2000, looks at the effect on motorcyclist deaths. We assume a proportional effect on injuries.

Farmer and Williams, 2005, reports the effect on passenger deaths. We assume a proportional effect on injuries.

Solomon, UImer, and Preusser, 2002, reports the effects that CIOT campaigns have on seat belt usage. Using Preusser et al., 2008, we converted this to a $5.4 \%$ reduction in injuries. We assume proportional effects on both injuries and deaths.

Leaf and Preusser, 2011, reports the effect on recidivism. The authors estimated that DWI offenders subject to impoundment had a $27 \%$ reduction in recidivism relative to offenders not subject to impoundment. We assume proportional effects on both injuries and deaths.

Wagenaar et al., 2000, presents estimates on several outcomes. We use a summary estimate of an $11 \%$ reduction that is reported in the Countermeasures That Work report (University of North Carolina Highway Safety Research Center, 2011). We assume proportional effects on injuries.

DeYoung, 1999, reports the decrease of crashes caused by DWI offenders. We assume a proportional effect on injuries and deaths caused drivers with previous DWI 


\begin{tabular}{lll}
\hline Intervention & \multicolumn{1}{c}{ Estimated Effect } & \multicolumn{1}{c}{ Source } \\
\hline $\begin{array}{l}\text { In-person license } \\
\text { renewal for older drivers }\end{array}$ & $\begin{array}{l}\text { convictions. } \\
\text { involvement rates for drivers } \\
\text { ages 55+ }\end{array}$ & $\begin{array}{l}\text { Tefft, 2014, compares states with in-person license } \\
\text { renewal for older drivers and those without. The author } \\
\text { found a 9\% decrease in fatal crashes for ages 55+ with } \\
\text { little evidence that this reduction varies significantly by age } \\
\text { in this range. }\end{array}$ \\
$\begin{array}{ll}\text { Higher fines for seat } \\
\text { belt-use violations }\end{array}$ & $\begin{array}{l}\text { Houston and Richardson, 2005, uses changes in state- } \\
\text { involving passenger vehicles }\end{array}$ & $\begin{array}{l}\text { level seat belt fines to estimate that a } \$ 1 \text { increase is } \\
\text { associated with a 0.152-percentage-point increase in seat } \\
\text { belt use, implying an 11.4\% increase for a } \$ 74 \text { fine. Using } \\
\text { Preusser et al., 2008, this increase translates to a } 7.2 \% \\
\text { decrease in fatalities. }\end{array}$ \\
\hline
\end{tabular}

NOTE: We assume all effects on injuries to be the same as those on deaths, except with sobriety checkpoints, for which the effect on injuries is 20 percent.

Table A.3. National Per-Injury and Per-Fatality Costs, in Dollars

\begin{tabular}{lcc}
\hline Cost Category & Cost per Injury & Cost per Fatality \\
\hline Medical & 3,805 & 11,883 \\
Emergency service & 88 & 947 \\
Market productivity & 4,436 & 979,925 \\
Household productivity & 1,501 & 304,406 \\
Insurance administration & 2,662 & 29,738 \\
Workplace cost & 503 & 12,372 \\
Legal costs & 1,225 & 111,812 \\
Travel delay & 1,308 & 6,006 \\
Property damage & 5,044 & 11,773 \\
\hline
\end{tabular}

SOURCE: Blincoe et al., 2015.

NOTE: Blincoe et al., 2015, Table 1-2, reports costs by injury severity. We calculated a weighted average using the relative frequencies of each injury severity type, in Table 5-14 of the 2014 issue of that report, and multiplied by 1.05 to adjust 2010 dollars to 2012 dollars. The revised report (Blincoe et al., 2015) fixes errors in the coding of the statistical analysis program; these lowered its estimates of the five cost categories (medical through legal costs) for injuries, but not fatalities. 



\section{References}

Blincoe, Lawrence, Ted R. Miller, Eduard Zaloshnja, and Bruce A. Lawrence, The Economic and Societal Impact of Motor Vehicle Crashes, 2010 (Revised), Washington, D.C.: National Highway Traffic Safety Administration, DOT HS 812 013, May 2015. As of August 12, 2015:

http://www-nrd.nhtsa.dot.gov/pubs/812013.pdf

Bureau of Labor Statistics, "May 2011 State Occupational Employment and Wage Estimates," last modified March 27, 2012; referenced February 19, 2014. As of August 12, 2015 : http://www.bls.gov/oes/2011/may/oessrcst.htm

$\mathrm{CDC}-\mathrm{See}$ Centers for Disease Control and Prevention.

Centers for Disease Control and Prevention, "Winnable Battles: Motor Vehicle Injuries,"

November 3, 2014; April 15, 2014, version referenced July 28, 2014. As of August 12, 2015 : http://www.cdc.gov/WinnableBattles/MotorVehicleInjury/

— , "WISQARSTM: Your Source for U.S. Injury Statistics," last updated August 12, 2015; July 10, 2014, version referenced July 22, 2014. As of August 12, 2015 :

http://www.cdc.gov/injury/wisqars/facts.html

Century Council, The National Agenda: A System to Fight Hardcore DWI, Appendix B: National Hardcore Drunk Driver Project, Arlington, Va., 2008.

Council for Community and Economic Research, "Cost of Living Index," undated; referenced July 22, 2014:

http://www.coli.org

Cunningham, Christopher M., Joseph E. Hummer, and Jae-Pil Moon, An Evaluation of the Safety Effects of Speed Enforcement Cameras in Charlotte, North Carolina, Raleigh, N.C.: Institute for Transportation Research and Education, North Carolina State University, 2005.

DeYoung, David J., "An Evaluation of the Specific Deterrent Effects of Vehicle Impoundment on Suspended, Revoked and Unlicensed Drivers in California," Accident Analysis and Prevention, Vol. 31, No. 1-2, January 1999, pp. 45-53.

DeYoung, David J., Helen N. Tashima, and Scott V. Masten, An Evaluation of the Effectiveness of Ignition Interlock in California: Technical Report, Sacramento, Calif.: California Department of Motor Vehicles, Research and Development Section, CAL-DMV-RSS-05217, September 2005. As of August 12, 2015: http://apps.dmv.ca.gov/about/profile/rd/r_d_report/Section_5/S5-217.pdf 
Ecola, Liisa, Benjamin Batorsky, and Jeanne S. Ringel, A New Tool to Help Decisionmakers Select Interventions to Reduce Traffic Crash Deaths and Injuries, Santa Monica, Calif.: RAND Corporation, RB-9827-CDC, forthcoming (a).

—_ How to Get the Biggest Impact from an Increase in Spending on Traffic Safety, Santa Monica, Calif.: RAND Corporation, RB-9855, forthcoming (b).

_ - Should Traffic Crash Interventions Be Selected Nationally or State by State? Santa Monica, Calif:: RAND Corporation, RB-9860, forthcoming (c).

Ecola, Liisa, and Jeanne S. Ringel, Which Behavioral Interventions are Most Cost-Effective in Reducing Drunk Driving? Santa Monica, Calif.: RAND Corporation, RB-9826-CDC, forthcoming.

Elder, Randy W., Ruth A. Shults, David A. Sleet, James L. Nichols, Stephanie Zaza, and Robert S. Thompson, "Effectiveness of Sobriety Checkpoints for Reducing Alcohol-Involved Crashes," Traffic Injury Prevention, Vol. 3, No. 4, 2002, pp. 266-274.

Farmer, Charles M., and Allan F. Williams, "Effect on Fatality Risk of Changing from Secondary to Primary Seat Belt Enforcement," Journal of Safety Research, Vol. 36, No. 2, 2005, pp. 189-194.

Fell, James C., A. Scott Tippetts, and Martin Levy, "Evaluation of Seven Publicized Enforcement Demonstration Programs to Reduce Impaired Driving: Georgia, Louisiana, Pennsylvania, Tennessee, Texas, Indiana, and Michigan," Annals of Advances in Automotive Medicine, Vol. 52, October 2008, pp. 23-38.

Governors Highway Safety Association, "SHSO Programs and Funding," undated; referenced June 19, 2015. As of August 12, 2015: http://www.ghsa.org/html/stateinfo/programs/index.html

Grant, Darren, and Stephen M. Rutner, "The Effect of Bicycle Helmet Legislation on Bicycling Fatalities," Journal of Policy Analysis and Management, Vol. 23, No. 3, Summer 2004, pp. 595-611.

Houston, David J., and Lilliard E. Richardson Jr., "Getting Americans to Buckle Up: The Efficacy of State Seat Belt Laws," Accident Analysis and Prevention, Vol. 37, No. 6, November 2005, pp. 1114-1120.

Hu, Wen, Anne T. McCartt, and Eric R. Teoh, "Effects of Red Light Camera Enforcement on Fatal Crashes in Large U.S. Cities," Journal of Safety Research, Vol. 42, No. 4, August 2011, pp. 277-282.

Leaf, William A., and David F. Preusser, Evaluation of Minnesota's Vehicle Plate Impoundment Law for Impaired Drivers, Washington, D.C.: National Highway Traffic Safety 
Administration, DOT HS 811 351, January 2011. As of August 12, 2015:

http://www.nhtsa.gov/staticfiles/nti/pdf/811351.pdf

National Center for Statistics and Analysis, Traffic Safety Facts 2013: A Compilation of Motor Vehicle Crash Data from the Fatality Analysis Reporting System and the General Estimates System, Washington, D.C.: National Highway Traffic Safety Administration, DOT HS 812 139, 2015. As of August 12, 2015:

http://www-nrd.nhtsa.dot.gov/Pubs/812139.pdf

National Highway Traffic Safety Administration, "Fatality Analysis Reporting System (FARS) Encyclopedia," undated (a); October 2, 2009, version referenced February 17, 2014. As of August 12, 2015:

http://www-fars.nhtsa.dot.gov/Main/index.aspx

_- "National Automotive Sampling System (NASS)," undated (b); referenced February 17, 2014. As of August 12, 2015:

http://www.nhtsa.gov/NASS

NHTSA — See National Highway Traffic Safety Administration.

Preusser, David F., Allan F. Williams, James L. Nichols, Julie Tison, and Neil K. Chaudhary, Effectiveness of Behavioral Highway Safety Countermeasures, Washington, D.C.:

Transportation Research Board, National Cooperative Highway Research Program Report 622, 2008. As of August 12, 2015: http://onlinepubs.trb.org/onlinepubs/nchrp/nchrp_rpt_622.pdf

Ringel, Jeanne S., Johanna Zmud, Kathryn Connor, David Powell, Brian G. Chow, Liisa Ecola, Christina Panis, and Gregory S. Jones, Costs and Effectiveness of Interventions to Reduce Motor Vehicle-Related Injuries and Deaths: Project Report and Online Tool Documentation, Santa Monica, Calif.: RAND Corporation, TL-144/1-CDC, forthcoming.

Sass, Tim R., and Paul R. Zimmerman, "Motorcycle Helmet Laws and Motorcyclist Fatalities," Journal of Regulatory Economics, Vol. 18, No. 3, November 2000, pp. 195-215.

Solomon, Mark G., Robert G. Ulmer, and David F. Preusser, Evaluation of Click It or Ticket Model Programs, Washington, D.C.: National Highway Traffic Safety Administration, DOT HS 809 498, September 2002. As of August 12, 2015: http://www.nhtsa.gov/people/injury/research/clickitcomposite/clickit_composite.pdf

Tefft, Brian C., Driver License Renewal Policies and Fatal Crash Involvement Rates of Older Drivers, United States, 1985-2011, AAA Foundation for Traffic Safety, July 2014. As of August 12, 2015:

https://www.aaafoundation.org/sites/default/files/OlderDriverLicenseRenewalFINALFTSFORMAT.pdf 
University of North Carolina Highway Safety Research Center, Countermeasures That Work: A Highway Safety Countermeasure Guide for State Highway Safety Offices, 6th ed., Washington, D.C.: National Highway Traffic Safety Administration, 2011. As of August 12, 2015:

http://www.nhtsa.gov/staticfiles/nti/pdf/811444.pdf

Wagenaar, Alexander C., T. S. Zobeck, G. D. Williams, and R. Hingson, Effects of DWI Control Efforts: A Systematic Review of the Literature from 1960-1991, Minneapolis, Minn.:

University of Minnesota, School of Public Health, 2000.

World Health Organization, Decade of Action for Road Safety 2011-2020 Global Launch, Geneva, Switzerland, WHO/NMH/VIP11.08, 2011. As of August 12, 2015: http://www.who.int/roadsafety/publications/global_launch.pdf

- Strengthening Road Safety Legislation: A Practice and Resource Manual for Countries, 2013. As of August 12, 2015:

http://www.who.int/violence_injury_prevention/road_traffic/countrywork/legislation_manual /en/ 